\title{
DEVELOPMENT OF DOPED NANOPOROUS CARBONS FOR HYDROGEN STORAGE
}

\section{FINAL SCIENTIFIC REPORT}

Reporting Period: January 1, 2006 - March 31, 2010

Principal Authors: Angela D. Lueking, ${ }^{1}$ Qixiu Li

With Contributions from: John V. Badding, Dania Fonseca, Humerto Gutierrez, Apurba Sakti, Kofi Adu, Michael Schimmel

August 3, 2010

DOE Award Number: DE-FG26-06NT42733

Submitting Organization:

The Pennsylvania State University

Office of Sponsored Programs

110 Technology Center

University Park, PA 16802 


\section{DISCLAIMER:}

This report was prepared as an account of work sponsored by an agency of the United States Government. Neither the United States Government nor any agency thereof, nor any of their employees, makes any warranty, express or implied, or assumes any legal liability or responsibility for the accuracy, completeness, or usefulness of any information, apparatus, product, or process disclosed, or represents that its use would not infringe privately owned rights. Reference herein to any specific commercial product, process, or service by trade name, trademark, manufacturer, or otherwise does not necessarily constitute or imply its endorsement, recommendation, or favoring by the United State Government or any agency thereof. The views and opinions of authors expressed herein do not necessarily state or reflect those of the United States Government or any agency thereof. 


\begin{abstract}
Hydrogen storage materials based on the hydrogen spillover mechanism onto metal-doped nanoporous carbons are studied, in an effort to develop materials that store appreciable hydrogen at ambient temperatures and moderate pressures. We demonstrate that oxidation of the carbon surface can significantly increase the hydrogen uptake of these materials, primarily at low pressure. Trace water present in the system plays a role in the development of active sites, and may further be used as a strategy to increase uptake. Increased surface density of oxygen groups led to a significant enhancement of hydrogen spillover at pressures less than 100 milibar. At $300 \mathrm{~K}$, the hydrogen uptake was up to $1.1 \mathrm{wt}$ \% at $100 \mathrm{mbar}$ and increased to $1.4 \mathrm{wt} . \%$ at 20 bar. However, only $0.4 \mathrm{wt} \%$ of this was desorbable via a pressure reduction at room temperature, and the high lowpressure hydrogen uptake was found only when trace water was present during pretreatment. Although far from DOE hydrogen storage targets, storage at ambient temperature has significant practical advantages oner cryogenic physical adsorbents. The role of trace water in surface modification has significant implications for reproducibility in the field. High-pressure in situ characterization of ideal carbon surfaces in hydrogen suggests re-hybridization is not likely under conditions of practical interest. Advanced characterization is used to probe carbon-hydrogen-metal interactions in a number of systems and new carbon materials have been developed.
\end{abstract}




\section{Table of Contents}

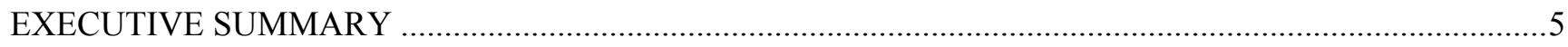

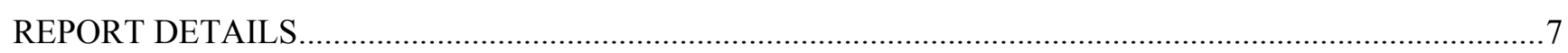

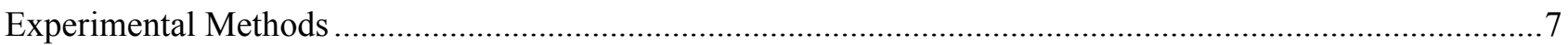

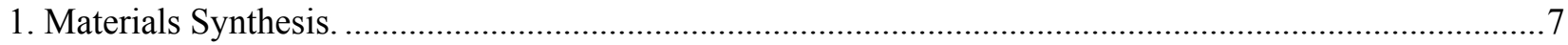

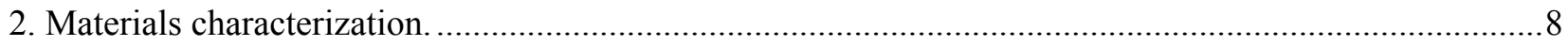

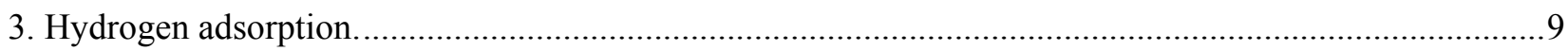

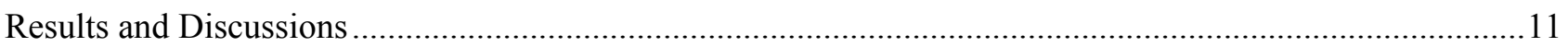

The Effect of Surface Oxygen Groups and Water on Hydrogen Spillover in Pt-doped Activated Carbon .. 13 Hydrogen/Water Desorption Temperatures from Oxygen-Modified Carbon-Based Spillover Materials....19

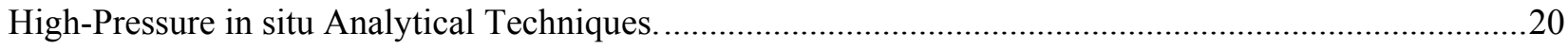

Other Peer-reviewed Publications Resulting from this Work...............................................................26

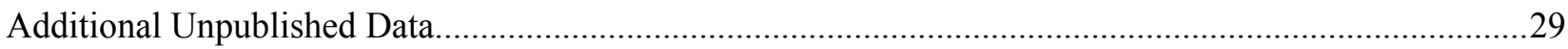

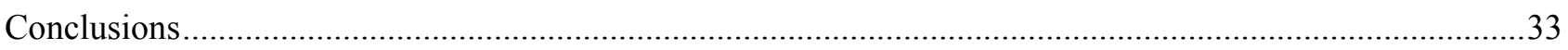

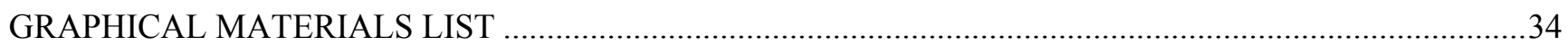

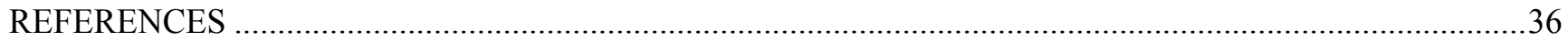

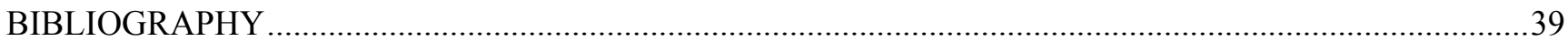

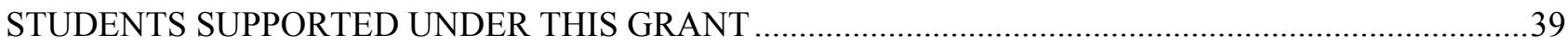

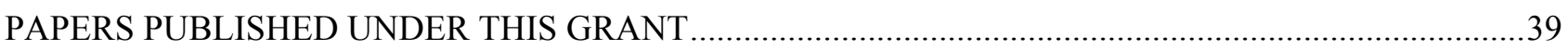

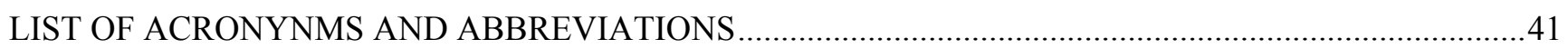




\section{EXECUTIVE SUMMARY}

The objective of the project was to understand the active adsorption sites in carbon materials that have been activated with nanocatalysts, and use this knowledge to enhance synergistic effects that create new adsorption sites and activate the carbon nanomaterials for adsorption in the DOE target temperature and pressure range. After extensive development and validation of hydrogen storage measurements, the main finding toward this goal was that oxygen functional groups could enhance hydrogen uptake via the hydrogen spillover mechanism, and surprisingly, that trace water present in the hydrogen supply during sample reduction played a major role in the development of active sites. Multiple surface characterization methods were used to better understand the role and nature of oxygen functional groups as active sites in the hydrogen spillover process. The results of a peer-reviewed paper that will be submitted in June 2010 will be particularly relevant and timely given recent publications concerning the reproducibility of hydrogen spillover in carbon-based samples. The role of water in the development of functional groups on carbon-based spillover samples may provide clues to differences between laboratories. Optimization of surface chemistry for hydrogen spillover can then move forward.

More specifically, a potassium hydroxide $(\mathrm{KOH})$ treatment was used to increase the surface density of oxygen groups on a high surface area activated carbon (AC), which served as a secondary receptor for hydrogen spillover after physical mixing with a common Pt-based spillover catalyst. Consistent with previous results, XPS showed that $\mathrm{KOH}$ treatment increased atomic concentration of oxygen and the fraction of carbonyl/quinone groups on the surface of the AC. Increased surface density of oxygen groups led to a significant enhancement of hydrogen spillover at pressures less than 100 milibar. At $300 \mathrm{~K}$, the hydrogen uptake was up to $1.1 \mathrm{wt} \%$ at $100 \mathrm{mbar}$ and increased to $1.4 \mathrm{wt} \%$ at $20 \mathrm{bar}$. However, only $0.4 \mathrm{wt} \%$ of this was desorbable via a pressure reduction at room temperature, and the high low-pressure hydrogen uptake was found only when trace water was present during pretreatment. The trace water was believed to affect the development of active surface sites, based on characterization of the development of oxygen groups by XPS and FTIR. The results also provide insight into the hydrogen spillover mechanism, and highlight the difference between hydrogen that is strongly chemisorbed on the metal, weakly chemisorbed on highly reactive carbon edge sites, physisorbed in micropores on the carbon support, and bound in a loose hydrogen spillover 'riding mode' (borrowing a term previously employed in the catalysis field). Temperature-Programmed Desorption studies of the oxidized carbon surfaces suggest low-temperature desorption of the spilled over hydrogen is possible, but highly dependent upon surface chemistry and material. Although the ultimate uptake of $1.4 \%$ at 20 bar does not meet targets, the scientific understanding gained by this report may serve to better optimize future materials. Further, the high hydrogen to metal ratio of up to 444 indicates an extremely high amount of hydrogen spillover at low pressure, one of the highest in the catalysis literature. Additional evidence for hydrogen spillover at extremely low pressure $\left(10^{-6} \mathrm{mbar}\right)$ was found. The observation of this degree of hydrogen at pressures less than 100 mbar suggests the metal-doped carbon material behave more like a metal hydride than its nanoporous carbon component that makes up over $90 \%$ of its mass. These findings have practical implications in the design and use of hydrogen spillover materials in mobile applications. For example, a 'temperature-swing' may be required to fully utilize these materials, particularly if part of the spilled over hydrogen is weakly chemisorbed to the surface. The role of water in activating (and deactivating) the surface will also have practical implications to the use of spillover materials in real-world applications.

At the time this project was started, theoretical predictions suggested that induced defects can and would arise from carbon-metal interactions and carbon could be rehybridized by high-pressure and/or chemisorbed hydrogen. In this context, a major component of the project was the development and implementation of in situ high-pressure analytical techniques to experimentally test these theoretical predictions. The high pressure in situ characterization methods relied heavily on Multi-wavelength Raman spectroscopy, which is a powerful probe of carbon structure, defect, and bonding in carbon, carbon-hydrogen, and catalytic metal-carbonhydrogen systems. Developed methods were designed to probe high pressure metal-carbon-hydrogen interactions, particularly upon the introduction of a spillover catalyst that provided a supply of readily diffusing 
hydrogen species. Probing the interactions at high-pressures led to results relevant to hydrogen storage applications rather than relying on extrapolation from low pressure characterization. Interestingly, no significant changes were observed in the Raman spectra of activated platinum-doped single-walled nanotubes upon exposure to $\mathrm{H}_{2}$ at $100 \mathrm{bar}$, even when the material was shown to take up $0.2 \mathrm{wt} \%$ hydrogen at $20 \mathrm{bar}$. Changes in the Raman spectra observed after heating were observed for both $\mathrm{H}_{2}$ and $\mathrm{He}$, and were dependent upon the excitation wavelength. The very subtle nature of the changes seen upon hydrogen exposure at extreme pressures led us to reprioritize the effort, and use characterization as a means to supplement material development rather than to guide the effort a priori.

During development of the characterization methods, tetrahedral amorphous carbons with various degrees of hydrogenation were used to validate methods. Unusual high-frequency Raman modes were found in these hydrogenated amorphous carbons, Multi-wavelength Raman spectroscopy probed changes in carbon structure at various stages of synthesis, and was also used to probe hydrogenation of these materials at high pressure. The process by which to synthesize the tetrahedral amorphous carbons from anthracite led to materials with a highly favorable porosity, and this can perhaps explain the evidence for the unusual carbon-hydrogen interactions found in these materials.

Various nanoporous carbon materials were synthesized and characterized over the course of this work, including carbon nanofibers and nanotubes, carbide-derived-carbons, and the exfoliated and etched graphite nanofibers that are exclusive to our laboratory. Methods were developed to co-dope magnesium and boron into the fiber structure, and this was shown to increase the thermal stability of these fibers. In total, the efforts led to a total of eight peer-reviewed papers (three published, one submitted, four in preparation) in carbon, and coalderived carbon, materials. Submission of the 'in preparation' papers is expected as the student funded on this project finalizes her Ph.D. thesis. The characterization results described above supported the findings of another DOE project that led to two patents in coal-derived materials, and further, the characterization results and collaboration forged in this work provided the basis for additional funding from DOE's Basic Energy Sciences Division, a rare cross-over from very applied coal-based carbon materials to the basic sciences.

The deliverable of this project at its inception was stated as follows: Correlation of information obtained from the high pressure in situ measurements, including characterization of (i) active surface sites, (ii) rehybridized carbon sites, and (iii) surface chemistry of the adsorbent with adsorption uptake and energies will result in site specific structure composition relationships. These site specific relationships will be incorporated into a feedback loop involving synthesis to allow for optimization of overall hydrogen uptake to meet DOE storage targets. Although not fully realized, we have provided a road map for future work to understand the role of oxygen and water on the formation of active sites. We have utilized the high-pressure in situ characterization to demonstrate that theoretically predicted rehybridization does not likely occur under conditions practical for hydrogen storage. The framework for the structure composition relationships with active sites is now possible. 


\section{REPORT DETAILS}

\section{Experimental Methods}

The theme of material synthesis is doped nanoporous carbons for hydrogen storage via the hydrogen spillover mechanism. Thus, the three main components of the work were (1) Synthesis of various metal-loaded nanoporous carbons, which included (a) synthesis, optimization, and modification of the nanopoous carbon, and (b) introduction of metal, and optimization of its dispersion; (2) Characterization of the nanoporous carbons, both before and after metal-loading, and at various stages of hydrogen exposure; and (3) Assessment of hydrogen uptake

\section{Materials Synthesis.}

Various nanoporous carbon materials (a.k.a. 'supports') were used over the course of this project, in an attempt to optimize carbon properties for hydrogen spillover. The synthesized nanoporous carbons include: graphite nanofibers (GNF), exfoliated graphite nanofibers (EGNF), reactively ball-milled anthracites (RBMAs), and multi-walled carbon nanotubes (MWNT). Commercially available carbons used include: activated carbons (AC) and single-walled carbon nanotubes (SWNT). Several carbons were modified after synthesis, in particular, the $\mathrm{AC}$ was modified with an oxidation treatment, described below. More details on synthesis are described briefly below.

1a. Graphite Nanofibers and Exfoliated Graphite Nanofibers. GNF and EGNF were originally selected as the carbon support for doping, due to the potential to selectively tune the graphitic order (of GNF) and pore size (of EGNF). Synthesis of GNF and EGNF is described elsewhere. ${ }^{2-4}$ Typically, GNFs were synthesized by passing an ethylene-hydrogen mixture (in various predetermined ratios) over an iron-nickel catalyst at elevated temperatures (e.g., $600^{\circ} \mathrm{C}$ ). In certain cases, GNFs were treated in air at elevated temperatures (e.g. $390^{\circ} \mathrm{C}$ for 10 minutes) to remove any carbon atoms at the fiber surface which may obstruct the incorporation of the dopant into the nanofiber. EGNF were synthesized by intercalating the GNF with an oxidizing acid mixture (e.g., 1 $\mathrm{HNO}_{3}: 1 \mathrm{H}_{2} \mathrm{SO}_{4}$ ), heating the intercalated GNF to high temperatures (from 700-1000 ${ }^{\circ} \mathrm{C}$ ), and in certain cases, exposing the produce to 20 bar $\mathrm{H}_{2}$. In certain cases, this led to exfoliation, and in certain cases this led to etching of the GNF rather than exfoliation.

Methods to intercalate GNF with magnesium and boron were explored. The doping experiments were performed in vacuum-sealed ( $\sim 5 \times 10^{-6}$ Torr) quartz ampoules containing a mixture of $100 \mathrm{mg}$ of GNF with 63.7 $\mathrm{mg}$ of $\mathrm{MgB}_{2}$ (previously ground in argon atmosphere). After sealing, the ampoules were heated at either (1) $900^{\circ} \mathrm{C}$ for $9 \mathrm{~h}$ or (2) $1000{ }^{\circ} \mathrm{C}$ during $6 \mathrm{~h}$. In order to explore the influence of the fiber crystalline quality (graphitic order) on the incorporation of $\mathrm{Mg}$ and $\mathrm{B}$ into the nanostructure, the GNF precursor was thermally treated at $2000{ }^{\circ} \mathrm{C}$ in Argon.

1b. Carbon Nanotubes and Pt-doped SWNT. SWNT was obtained from a commercial supplier (HiPco 8 ; Carbon Nanotechnologies Inc.), and the as-received SWNT contained less than $15 \mathrm{wt} \%$ ash content as reported by the manufacturer, and was confirmed with temperature programmed oxidation in our laboratory to be $14.8 \%{ }^{5}$ The SWNTs were doped with Pt via incipient wetness with $\mathrm{H}_{2} \mathrm{PtCl}_{6}$, to lead to an overall loading of $1 \% \mathrm{Pt} / \mathrm{SWNT}$. Prior to analysis, the $1 \% \mathrm{Pt} / \mathrm{SWNT}$ was reduced in $200{ }^{\circ} \mathrm{C} \mathrm{H}_{2}$ at a rate of $100 \mathrm{cc} / \mathrm{min}$. This pretreatment step was conducted in situ on the gravimetric adsorption analysis. For Raman measurements, the sample was reduced in a custom-made flow reactor, then transferred to a high-pressure capillary device in an inert atmosphere.

Also used were multi-walled carbon nanotubes (MWNT). The MWNT were synthesized in a procedure described elsewhere. ${ }^{6}$ Synthesis is similar to that of GNF described above, but NiMgO catalyst is used with pure methane. 
1c. Reactively Ball Milled Anthracites. Synthesis of RBMAs is described elsewhere. ${ }^{7}$ In brief, ball milling was done on a Fritsch Planetary Mono Mill Pulverisette 6 LC - 106A with a $250 \mathrm{ml}$ stainless steel (Fe-Cr-Ni) vessel and a set of twenty $10 \mathrm{~mm}$ diameter stainless steel balls. The samples were generally milled for 80 hours at $400 \mathrm{rpm}$ in ultra-high purity $(99.99999 \%)$ grade argon atmosphere to prevent oxidation and minimize air exposure. Cyclohexene (99\% purity, JT Baker) was added in the ratio of $6 \mathrm{~g}$ solid to $20 \mathrm{ml}$. In select cases, graphite was substituted for anthracite (RBMG).

1d. Carbide-derived-carbons. Synthesis of CDCs is based on the work of Gogotsi et al. ${ }^{8}$ The carbide precursor was placed into the quartz tube of a vertical tube furnace. The tube was then heated to the desired temperatures under Argon purge. Once the desired temperature was reached, chlorine gas (GTS, 99.5\%) was passed through the tube at a flow rate of $10-15 \mathrm{~cm}^{3} / \mathrm{min}$. After chlorination, the furnace was cooled to room temperature under Argon purge. ${ }^{9}$ Select samples were annealed in $\mathrm{H}_{2}$ at $600{ }^{\circ} \mathrm{C}$ for $2 \mathrm{hrs}$. The precursors applied were Titanium carbide $(\mathrm{TiC})$ and Boron carbide $\left(\mathrm{B}_{4} \mathrm{C}\right)$. The synthesis time ranged from $3 \mathrm{hrs}$ to $6 \mathrm{hrs}$.

1e. Activated Carbons and Oxidized Activated Carbons. A high surface area AC (The Kansai Coke \& Chemicals Co.) was selected for study. This AC is originally prepared by petroleum coke. To further increase surface oxygen groups, the as-received $\mathrm{AC}$ was treated with $\mathrm{KOH}$, drawing from a procedure adapted from that reported by Chiang et al. ${ }^{10}$ The procedure was modified to use $\mathrm{KOH}$ rather than $\mathrm{NaOH}$. The AC was impregnated with $1 \mathrm{M}$ potassium hydroxide ( $\mathrm{KOH}$, EMD chemicals, Inc.) in a $\mathrm{KOH}$ to $\mathrm{AC}$ weight ratio 4:1, magnetically stirred for $12 \mathrm{~h}$ at room, washed to neutral, filtered, then dried at $373 \mathrm{~K}$. The resulting material after $\mathrm{KOH}$ activation will be referred to as $\mathrm{AC}-\mathrm{o}$.

1f: Doping of $A C$ and AC-o by Physical Mixing. For the AC and AC-o studies, the presence of oxygen groups on the carbon support is expected to affect metal dispersion. Thus, secondary spillover studies were used to emphasize the role of surface chemistry without altering the 'supply' of the hydrogen species from the catalyst. The secondary carbon support (either AC or AC-o) was mixed with a Pt catalyst supported on activated carbon (5\% Pt-C, STEM Chemicals), in a ratio of Pt-C to AC fixed at 1:9, then ground with an agate mortar and pestle for $30 \mathrm{~min}$ (Pt-C/AC or Pt-C/AC-o).

\section{Materials characterization.}

2a. Multi-wavelength resonance micro-Raman spectroscopy (MWR) was used to characterize how much atomic hydrogen is chemically bonded to the carbon and the hybridization state $\left(\mathrm{sp}^{2} \mathrm{vs} \mathrm{sp}\right)$ of the carbon. The RBMA were used to establish methods to differentiate and track carbon, and carbon-hydrogen, Raman modes to establish how hydrogenation of amorphous carbons may be manifested in Raman spectroscopy. Details of the use of (MWR) is described in detail elsewhere. ${ }^{11}$ In brief, Raman spectra were collected on Renishaw inVia spectrometers with Leica DM LM microscope and a thermal electrically cooled CCD detector. $244 \mathrm{~nm}$ (UV) was obtained with a frequency doubled argon laser, while $514 \mathrm{~nm}$ (green) was obtained from an argon ion laser and $633 \mathrm{~nm}$ (red) excitation from a HeNe ion laser. At least three measurements were done per sample to probe different sample locations and check for reproducibility. Raman spectra are plotted without baseline subtraction unless otherwise noted.

2b. In Situ High-Pressure Characterization. The sample was inserted into a quartz capillary (0.030 " ID x $1 / 16 "$ OD) with one end closed. The open end of the capillary was then attached to a small pressurized chamber with a pressure gauge and a valve attached. All the above procedures are completed in the glove box. High pressure $\mathrm{H}_{2}$ can be released to the capillary when Raman experiments are performed. In certain cases, $\mathrm{Pt} / \mathrm{SWNT}$ used in this portion of the study were pretreated ex situ in $\mathrm{H}_{2}$ prior to transfer to the capillary tube. In other cases, $\mathrm{Pt} / \mathrm{SWNT}$ samples were treated at high temperature in a custom-made flow reactor that allowed transfer to the Raman capillary in an inert atmosphere. 
2c. Structural Characterization. Other standard methods were used to assess the structure of the various carbon materials used in these studies. BET specific surface area and total pore volume were calculated from nitrogen adsorption/desorption isotherms at $77 \mathrm{~K}$ with Micromeritics ASAP 2020. The micropore volumes were calculated from $\mathrm{CO}_{2}$ isotherms using the Dubinin-Astakhov (DA) equation. Before both $\mathrm{N}_{2}$ and $\mathrm{CO}_{2}$ isotherms, the samples were outgassed at elevated temperature in vacuum, typically $2 \mathrm{~mm} \mathrm{Hg}$ for 6 hours at $423 \mathrm{~K}$. Temperature Programmed Oxidation (TPO) studies were performed in a Perkin Elmer TGA 7 thermogravimetric analyzer by flowing ultra high purity (UHP) grade air with a flow rate of $100 \mathrm{cc} / \mathrm{min}$. Samples $\left(\sim 12 \mathrm{mg}\right.$ ) were heated from $30{ }^{\circ} \mathrm{C}$ to $1000{ }^{\circ} \mathrm{C}$ at $5^{\circ} \mathrm{C} / \mathrm{min}$. Transmission Electron Microscopy (TEM) was used as a determinant of carbon structure. Specimens for TEM were prepared by ultrasonic dispersion of the sample in isopropanol and then a drop of the suspension was applied to a Lacey carbon film. High Resolution Transmission Electron Microscopy (HRTEM), Electron Energy Loss Spectroscopy (EELS), and Energy-Dispersive $X$-ray Spectroscopy (EDS) were performed in a JEOL-2010F microscope. This technique allows us to establish a direct correlation between the diameter, morphology, crystalline structure and the $\mathrm{Mg}$ and B concentrations in individual MgB-doped GNF. Carbon structure was determined via X-ray Diffraction $(X R D)$ with a Philips X'Pert MPD, with $\mathrm{Cu} \mathrm{K} \alpha$ radiation. The sample was pressed into a quartz sample holder to obtain a smooth flat surface. Diffraction patterns were recorded over a range of $2 \theta$ angles from 10 to $90^{\circ}$ using 1 second per step. The d-spacing $\left(\mathrm{d}_{002}\right)$ and crystallite size $(\mathrm{Lc})$ was obtained. A silicon standard reference (640b) was used to calibrate the instrument.

2d. Surface Chemistry Characterization. The chemical bonding information of the modified surface was obtained by X-ray photoelectron spectroscopy (XPS) (Axis Ultra; Kratos). X-ray source for the measurement was monochromatic Al K-Alpha. The working pressure was maintained under $10^{-8}$ torr. $80 \mathrm{eV}$ pass energy was used for surveys and $20 \mathrm{eV}$ was for high-resolution scans. For calibration purpose, the $\mathrm{C}$ (1s) electron bond energy was referred at $284.6 \mathrm{eV}$, which is corresponding to graphitic carbon. ${ }^{12}$ Samples were exposed to air prior to characterization. We make the assumption that air exposure during sample transfer is expected to have minimal effect on the surface groups that remain chemically bound to the surface and could not be desorbed; our data show similar results regardless of time between synthesis/adsorption and characterization. Diffuse reflectance infrared spectra (DRIFTS) were collected on a Magna-IR 750 Nicolet Fourier-Transfer Infrared (FTIR) spectrometer in the range of $500-4000 \mathrm{~cm}^{-1}$ by diffuse reflectance spectroscopy (DRIFTS). All the FTIR spectra were collected at $50{ }^{\circ} \mathrm{C}$. Samples were exposed to air prior to characterization.

\section{Hydrogen adsorption.}

3a. Gravimetric Methods. Over the course of the project, two experimental set-ups were used. They are referred to as Set-up 1 and 2 herein. Set-up 1 can be considered the 'standard' measurement, and Set-up 2 was designed to emphasize the role of water on later adsorption studies. Set-up 1 is used, unless otherwise specified. Pretreatment and hydrogen adsorption were conducted on an Intelligent Gravimetric Analyzer (IGA)003 (Hiden Isochema), capable of pressures up to 20 bar and temperatures up to $\sim 500{ }^{\circ} \mathrm{C}$. Sample pretreatment was conducted in flowing gases, while adsorption was conducted in a static environment to eliminate drag effects. A turbomolecular pump is attached to IGA, allowing for a vacuum pretreatment at pressures of $10^{-6}$ mbar. Sample buoyancy corrections were made by using helium density measurements of the sample after the hydrogen isotherms were complete; thus, helium adsorption at room temperature is assumed to be minimal. Hydrogen adsorption/desorption isotherms were conducted at $25{ }^{\circ} \mathrm{C}$ at pressures under 20 bar. Adsorption temperature on the IGA was maintained by water bath. Data were collected at each pressure point until the mass was stabilized to within a $99 \%$ tolerance or for a maximum of 40 minutes, whichever was first. The precision of the IGA is $\pm 0.01 \mathrm{wt} \%$ for $100 \mathrm{mg}$ sample at $20 \mathrm{bar}( \pm 10 \mu \mathrm{g}){ }^{13}$

Samples containing hydrogen spillover catalysts (e.g. PtC/AC, PtC/AC-o, etc.) were pretreated using methods similar to those of Srinivas and Rao ${ }^{14}$ : the samples were first reduced in flowing hydrogen $(50 \mathrm{~mL} / \mathrm{min})$ at 250 ${ }^{\circ} \mathrm{C}$ for $6 \mathrm{~h}$ and then degassed in ultrahigh vacuum $\left(10^{-6} \mathrm{mbar}\right)$ at $400{ }^{\circ} \mathrm{C}$ for $8 \mathrm{~h}$, in certain instances the pretreatment times were varied as indicated. In Set-up 1, ultra-high-purity hydrogen (UHP, 99.999\%) and helium $(99.995 \%)$ were used for all pretreatments and measurements. Molecular sieve 3A purifiers were used 
on each gas stream in Set-up 1 to ensure purity was maintained in all experiments (see Fig. 1). In Set-up 2, $\mathrm{H}_{2}$ with increased purity (i.e. chemical grade $99.9999 \%$ ) was used without sending the gas through the 3A zeolite column. Set-up 2 also used a T-purge regulator and new gas delivery lines to the point of entry to the IGA system (see Fig. 1). This set-up was then modified to intentionally add water to the system by adding a water bubbler to a parallel $\mathrm{He}$ line; the water bubbler was installed in $\mathrm{He}$ line rather than $\mathrm{H}_{2}$ line due to safety concerns and is maintained at room temperature. With Set-up 2 a "Wet $\mathrm{H}_{2}$ " pretreatment is obtained as follows: first the indirect line is saturated with water using a He carrier gas that passes through the bubbler into the system at $30 \mathrm{~mL} / \mathrm{min}$ for 2 hours. The sample is then pretreated as described in Set-up 1 (i.e. $50 \mathrm{~mL} / \mathrm{min} \mathrm{H}_{2}$ at $250{ }^{\circ} \mathrm{C}$ for $6 \mathrm{~h}$; then $10^{-6} \mathrm{mbar}$ at $400{ }^{\circ} \mathrm{C}$ for $8 \mathrm{~h}$ ). The "Wet $\mathrm{H}_{2}$ " during pretreatment is thus obtained by residual water in the indirect line, and decreases as the experiment proceeds. Following the pretreatment, all hydrogen isotherms are collected at $25{ }^{\circ} \mathrm{C}$, in 'static' (i.e. non-flowing) mode on the IGA. The static mode maintains pressure in the system by using electronically controlled inlet and outlet valves that maintain the desired pressure in the system. In Set-up 1, with the use of the $3 \mathrm{~A}$ zeolite column, the same quality of $\mathrm{H}_{2}$ was used in pretreatment and adsorption. In Set-up 2, chemical-grade hydrogen was used for adsorption; in certain instances water was added through pre-saturation of the lines using saturated $\mathrm{He}$ in a manner similar to that described above for the pretreatment step. For clarity, Set-up 2 experiments are as follows:

a) $\mathrm{H}_{2}$ for both pretreatment and isotherms are dry ('d') chemical-grade hydrogen, no $\mathrm{H}_{2} \mathrm{O}$ was added in either stage (dPt-C/AC-o);

b) $\mathrm{H}_{2} \mathrm{O}$ was added only in the pretreatment stage by means of wet ('w') $\mathrm{H}_{2}$, chemical-grade $\mathrm{H}_{2}$ was used for isotherms (wPt-C/AC-o);

c) $\mathrm{H}_{2} \mathrm{O}$ was added in the pretreatment stage by means of "wet $\mathrm{H}_{2}$ ", followed by $\mathrm{H}_{2} \mathrm{O}$ isotherm using $\mathrm{He}$ as a carrier gas.

d) c was followed by $\mathrm{H}_{2}$ isotherm.

An attached mass spectrometer (MS; Hiden, DSMS type HPR-20) was used to determine the water content within the IGA at various stages of pretreatment. The inlet to the MS was placed at either the vacuum pump located at the outlet to the system such that it acted as a residual gas analyzer (RGA) during vacuum pretreatment, or at the outlet to the weighing chamber when the system was pressurized or operating in flow mode such that it operated as a TG-MS (IGA mode). The pressure of water in the adsorption chamber was determined by considering the relative intensity of the MS signals and the total pressure measured by transducers located in the chamber.

3b. Volumetric Methods. A high-pressure differential Sievert's unit incorporates a differential pressure transducer, automated valves, and Labview Control. These features increase the accuracy and precision of highpressure volumetric measurements: A differential pressure transducer monitors the pressure difference arising due to adsorption between identical sample and ballast volumes, thus further minimizing problems of accuracy of pressure readings and non-ideal gas corrections. Use of a Sievert's apparatus with a differential pressure transducer was reported to give reproducible hydrogen uptakes of $+/-0.1 \%$ for $100 \mathrm{mg}$ of sorbent. ${ }^{15}$ In our case, use of $100 \mathrm{mg}$ sample is calculated to give $0.2 \%$ error, based on both sample replicates and propagation of error.

3c. Temperature-Programmed Desorption (TPD). TPD experiments were conducted in conjunction with the gravimetric measurements on the IGA. The Hiden MS was operated in flowing RGA mode, with the inlet of the MS probing the vacuum chamber. TPD of oxygen-modified activated carbon (AC-o) and Pt-doped AC-o (Pt-C/AC-o) were performed in this experiment. Quartz samples were used to determine the background. In Method TPD-1, the sample was outgassed at $300 \mathrm{~K}$ at high vacuum, then the temperature of the IGA chamber was ramped at $5{ }^{\circ} \mathrm{C} / \mathrm{min}$. In Method TPD-2, the sample was outgassed at $77 \mathrm{~K}$ overnight; sample was allowed to heat to $300 \mathrm{~K}$ while monitoring MS signal and then ramped to $673 \mathrm{~K}$ with an external furnace at a rate of 5 ${ }^{\circ} \mathrm{C} / \mathrm{min}$. For all TPD data, MS signal is normalized per weight of sample. $\mathrm{T}_{\max }$ is defined as the temperature where the MS signal is maximum. 


\section{Results and Discussions}

Validation of Hydrogen Storage Methods. The field of hydrogen adsorption is plagued by erroneous reports and irreproducible data. Therefore, it was essential to validate methods, and a large amount of time was spent on validation, training, and equipment modifications. The IGA was initially calibrated with $\mathrm{LaNi}_{5}$, a metal hydride standard with known hydrogen uptake. Figure 1 shows a comparison of $\mathrm{LaNi}_{5}$ (a) measured on the IGA; (b) versus published literature data, and (c) obtained with the differential Sieverts. Collection of data with standards served as a means to train users on the equipment and ensure proper operation. It was found that $\mathrm{LaNi}_{5}$ adsorption data was highly dependent upon activation procedure, and further, activation procedure varied between the equipment in the two methods of adsorption. Thus, GX-31 was used as a validation tool, and compared against published data. ${ }^{16}$ The GX-31 activation is simpler, and physisorption to GX-31 provides adsorption in comparable pressure ranges to those expected in these studies (up to 100 bar). The hydrogen uptake of GX-31 obtained on our volumetric system matched closely to published reports ${ }^{16}$, both at ambient temperature (Figure 2a), and near-ambient temperatures $\left(0{ }^{\circ} \mathrm{C}\right.$ and $50{ }^{\circ} \mathrm{C}$, Figure $\left.2 \mathrm{~b}-\mathrm{c}\right)$. Collecting adsorption data at temperatures other than ambient requires special technique for volumetric measurements, as the moles adsorbed are a function of temperature (calculated from applicable gas laws). The measurement is further complicated by temperature gradients in the system, as the manifold and sample temperatures are different. This problem is minimized for a symmetric differential Sievert's apparatus, but slight asymmetries in the equipment may lead to experimental artifacts. Thus, it is important to calibrate the equipment at the temperature of interest to ensure there is no significant artifact in adsorption measurements when a temperature gradient is introduced. Completion of the measurements at $0{ }^{\circ} \mathrm{C}$ and $50{ }^{\circ} \mathrm{C}$ required calibration of the equipment with helium to measure helium "free space" as a function of adsorption temperature.
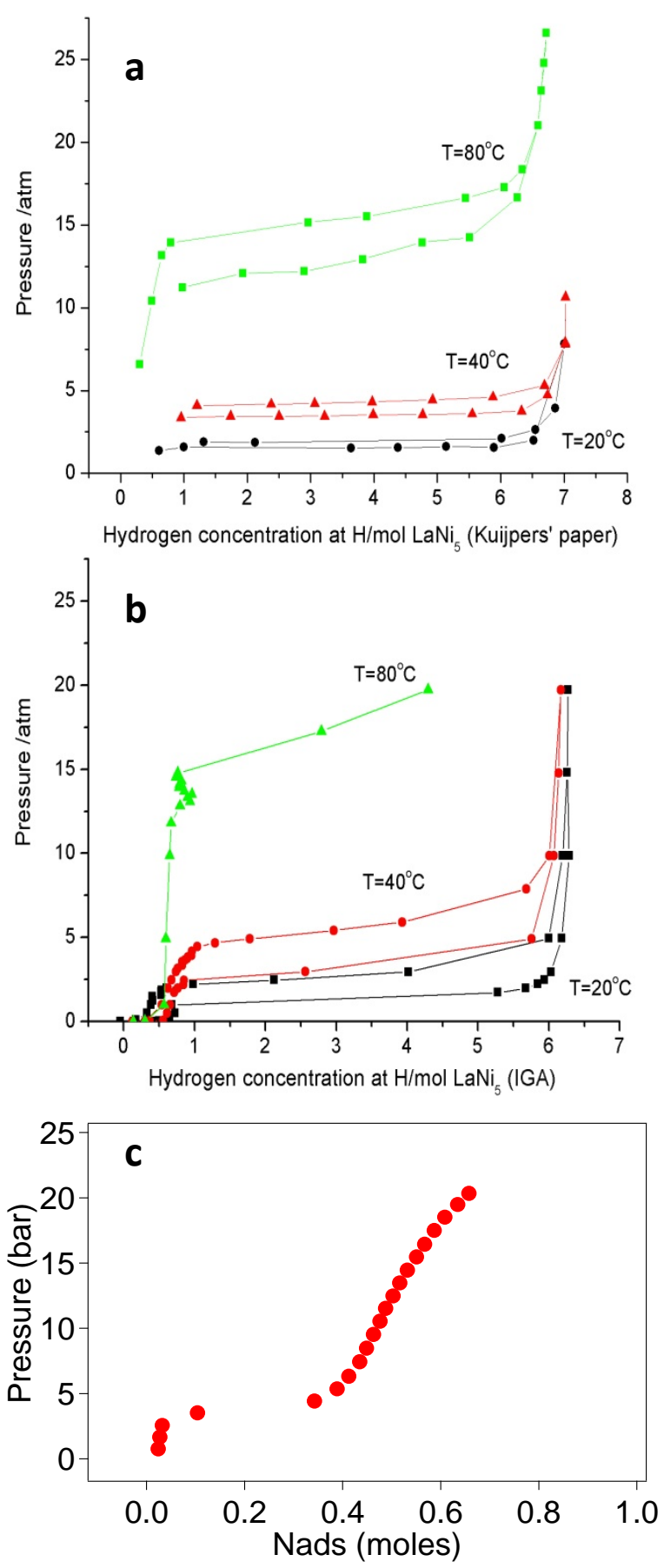

Figure 1: Adsorption isotherms for LaNi5, (a) measured on the IGA, (b) from published data, and (c) measured at $20^{\circ} \mathrm{C}$ on the volumetric equipment.

Calcium oxalate hydrate was used as a standard test of the TG-MS equipment ( $200 \mathrm{ml} / \mathrm{min}$ Helium at 1000 mbar total pressure, heating to $550{ }^{\circ} \mathrm{C}$ at $10^{\circ} \mathrm{C} / \mathrm{min}$ ). Validation of the TG-MS is shown in Figure 3 . The gases desorbed and weight loss are in consistent with the standard profile. Validation of the TPD Method-2 for Pd powder and nanosized Pd on activated carbon is shown in Figure 4 and compared against a quartz TPD blank in Figure 5. 

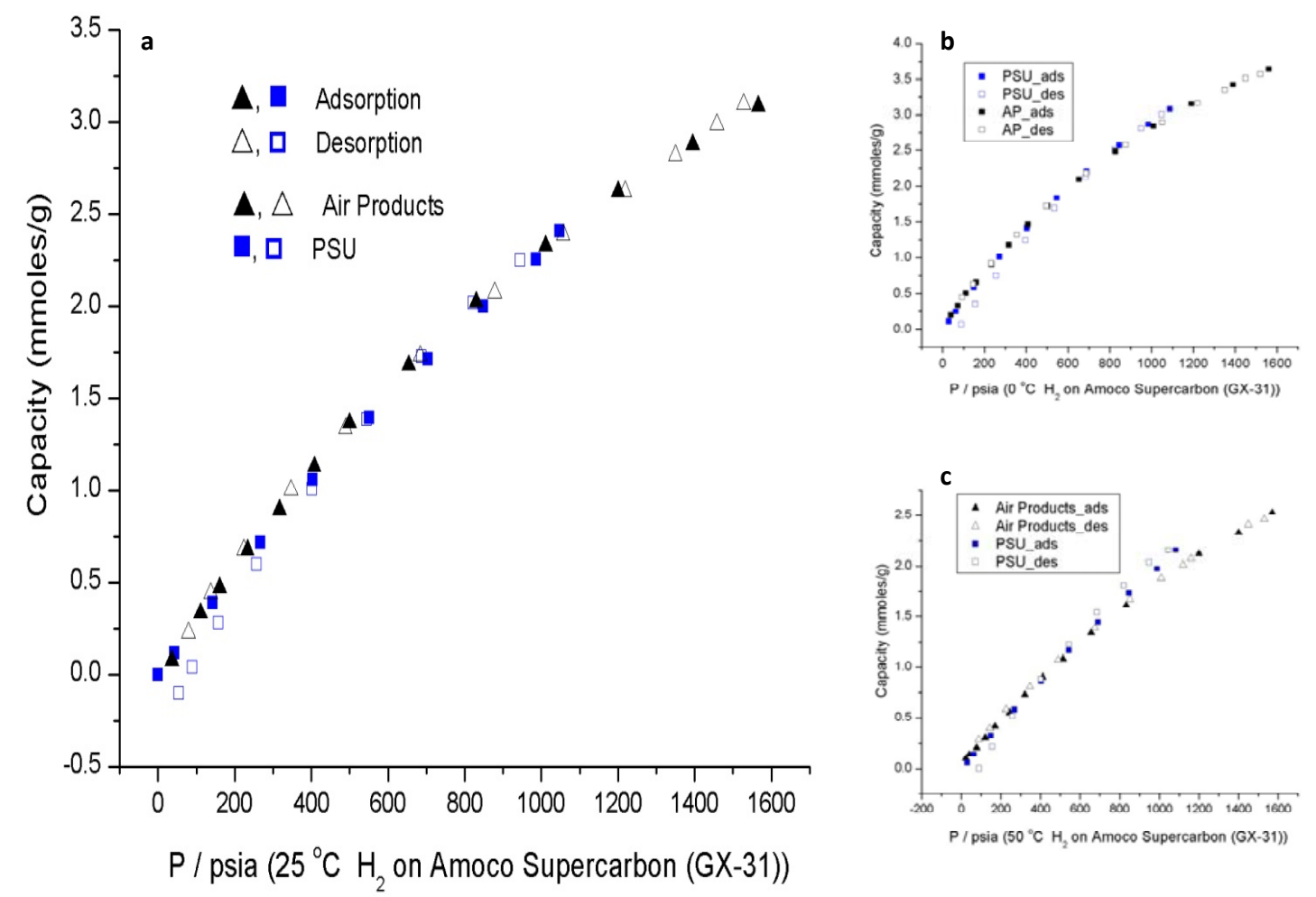

Figure 2: Volumetric adsorption data for GX-31 Amoco activated carbon matches published literature reports, thus verifying the measurement and the newly developed equipment. (a) ambient temperature of $25{ }^{\circ} \mathrm{C}$; (b) $0{ }^{\circ} \mathrm{C}$, and (c) $50{ }^{\circ} \mathrm{C}$.
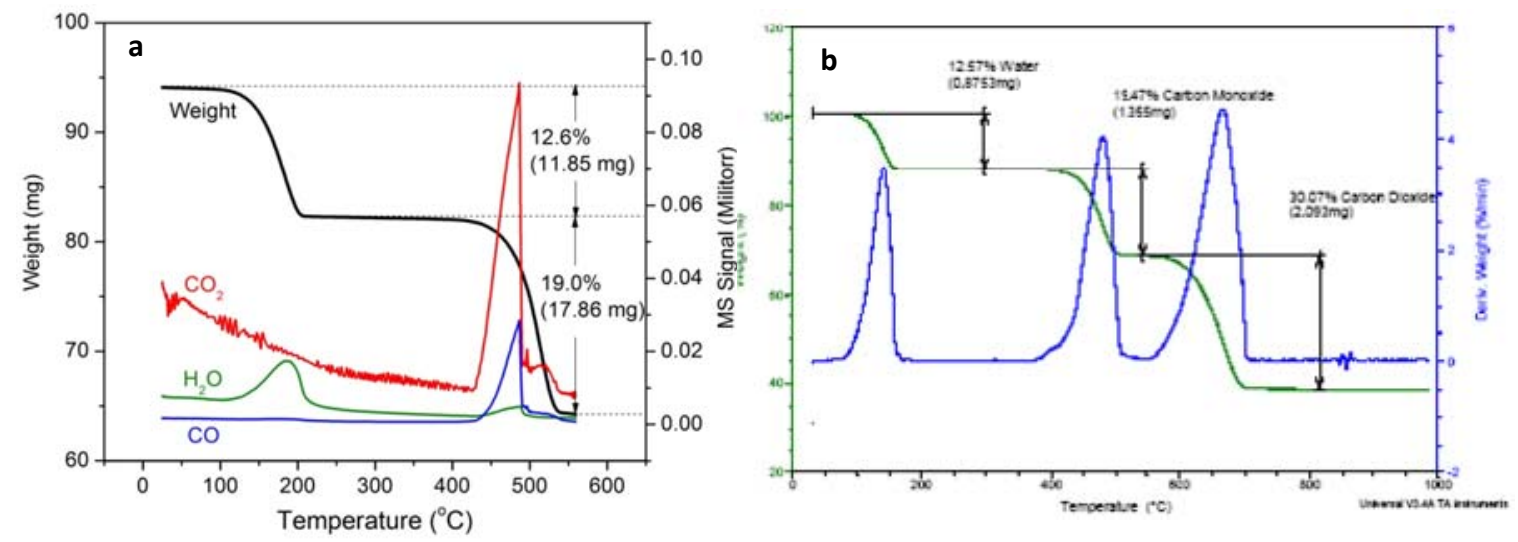

Figure 3: Calibration of the TG-MS with calcium oxalate hydrate: (a) our equipment vs. (b) manufacturer data. 

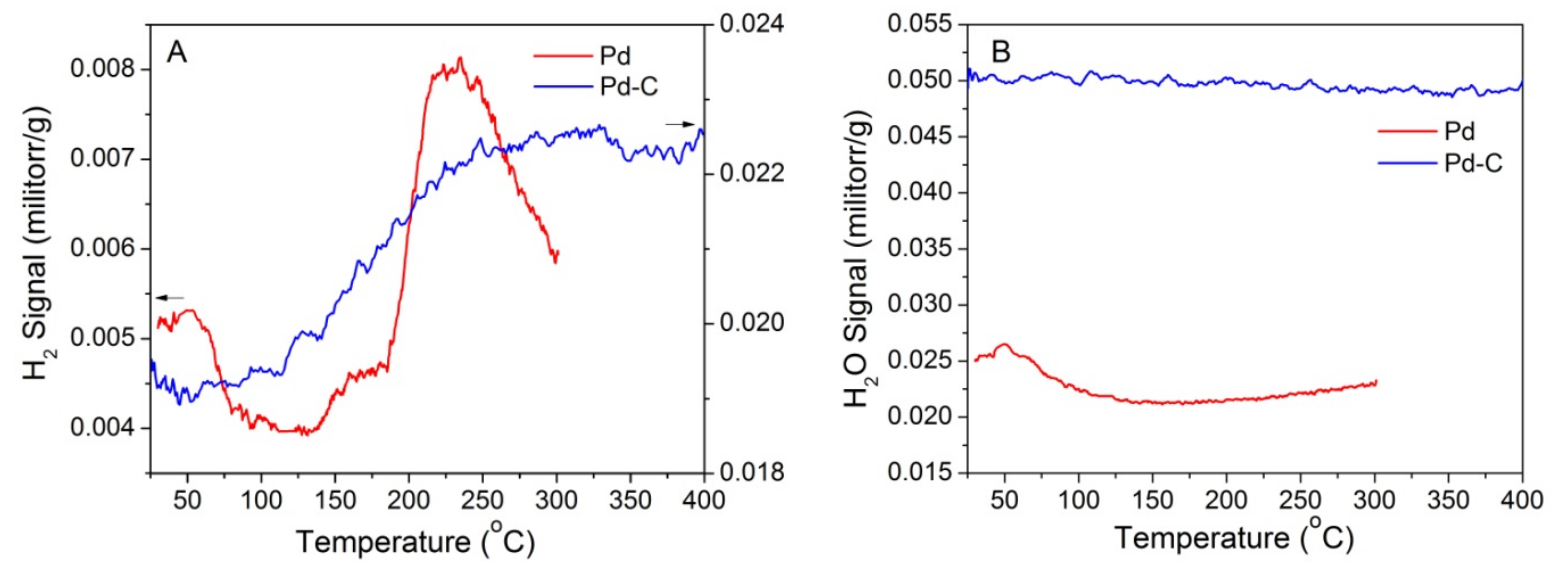

Figure 4: TPD spectra of Pd and Pd-C used to validate TPD Method-2. (A) $\mathrm{H}_{2}$ signal; (B) $\mathrm{H}_{2} \mathrm{O}$ signal. All signals were normalized on per gram basis.

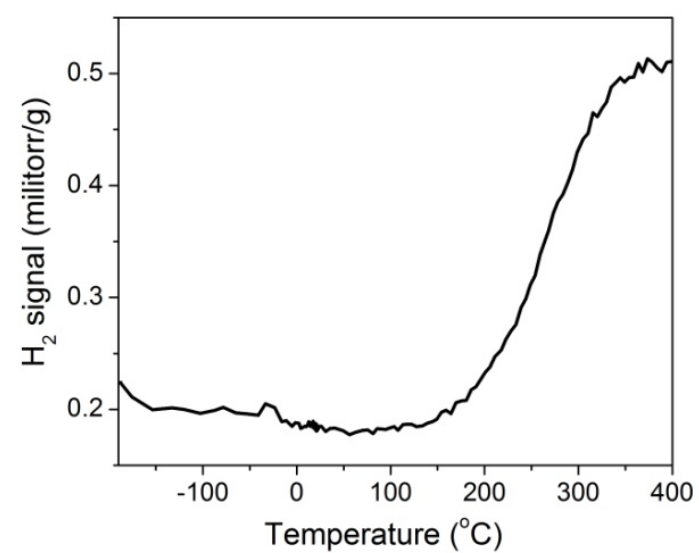

Figure 5: TPD spectra of quartz after $\mathrm{H}_{2}$ adsorption at $250{ }^{\circ} \mathrm{C}$ suggests desorption from the internals of the stainless steel reactor is possible and must be considered in analysis of the TPD spectra. Here, sample was not degassed after adsorption prior to cooling to room temperature to take the TPD measurement.

The Effect of Surface Oxygen Groups and Water on Hydrogen Spillover in Pt-doped Activated Carbon

The primary research outcome related to the original project goals concerns the effect of surface chemistry on the hydrogen spillover process. We found that hydrogen uptake via spillover can be enhanced by oxidation of the carbon surface. Unexpectedly, we also found that trace water present in the adsorption equipment can affect the develpment of the oxygen functional groups during preatrement. This finding may explain issues with reproducibility of hydrogen spillover on carbon-based samples, both in our own work, and in the outside community. These findings were submitted to the Journal of Physical Chemistry C in June 2010. ${ }^{17}$ Excerpts from this publication are reported below. As this section provides the primary findings of this work related to the original project objectives, geater detail is given of this paper than subsequent papers.

Overview (Abstract of the Submitted Paper). The synergistic role of increased oxygen functional groups and water on hydrogen adsorption via hydrogen spillover are explored. A potassium hydroxide (KOH) 
treatment is used to increase the surface density of oxygen groups on a high surface area activated carbon (AC), which serves as a secondary receptor for hydrogen spillover after physical mixing with a common Pt-based spillover catalyst. Consistent with previous results, XPS shows that $\mathrm{KOH}$ treatment increases atomic concentration of oxygen and the fraction of carbonyl/quinone groups on the surface of the AC. Increased surface density of oxygen groups leads to a significant enhancement of hydrogen spillover at pressures less than 100 milibar. At $300 \mathrm{~K}$, the hydrogen uptake is $1.1 \mathrm{wt} \%$ at $100 \mathrm{mbar}$ and increases to $1.4 \mathrm{wt} \%$ at 20 bar. However, only $0.4 \mathrm{wt} \%$ of this is desorbable via a pressure reduction at room temperature, and the high lowpressure hydrogen uptake is found only when trace water is present during pretreatment. The trace water is believed to affect the development of active surface sites, based on characterization of the development of oxygen groups by XPS and FTIR. The synergistic role of oxygen groups and water, and a plausible mechanism on the effect on hydrogen isotherms is discussed.

Main Findings. (Conclusion Section of the Submitted Paper w/ Related Supporting Figures.) In the current study, XPS characterization results show that $\mathrm{KOH}$ treatment produces oxygen groups on an activated carbon sample, with a large fraction being quinone type groups (Table 2, Figure 6). The oxidation treatment has a negligible effect on physisorption (AC vs. AC-o in Table $1 \&$ Figure 7), but leads to a significant enhancement of hydrogen adsorption in the presence of a hydrogen-dissociation catalyst, i.e. hydrogen spillover (Pt-C/AC-o $>$ Pt-C/AC in Figure 7). Gravimetric adsorption measurements show hydrogen spillover to the oxidized surface is pronounced at low pressures $(\mathrm{P}<100 \mathrm{mbar})$, with a $\mathrm{H}: \mathrm{M}_{\mathrm{T}}$ ratio of 444 , and a 7 -fold increase in overall hydrogen uptake relative to its constituents. The presence of water during pretreatment (in Setup-2) is necessary to realize this low-pressure enhancement (Figure 8), and we use XPS data and mass spectroscopy to provide evidence that this is due to increased oxygen functional groups formed during pretreatment in the presence of water and/or active carbon sites formed via gasification. The mechanism for the water-assisted pretreatment needs further clarification, as does its alignment with several proposed mechanisms on the effect of surface chemistry on hydrogen spillover. The pronounced low-pressure effect agrees with other publications, but is expected to be highly dependent on the nature of the sample. The current results indicate that oxidation of the surface of the support will facilitate low-pressure, ambient-temperature hydrogen spillover, but may not necessarily lead to hydrogen that readily desorbs at ambient temperature. XPS (Figure 9) and FTIR (Figure 10) surface characterization after $\mathrm{H}_{2}$ desorption suggests strongly bound hydrogen forms hydroxyls with introduced functional groups: there is only a vague indication of new carbon-hydrogen bonds in FTIR. A certain fraction of hydrogen is found to be loosely bound, in that it readily desorbs with pressure reduction and cannot be accounted for by physisorption to the carbon materials (based on adsorption versus desorption, and physisorption expected for AC, in Figure 7 and Figure 8). However, the state of this loosely bound hydrogen cannot be determined without in situ methods. The lack of hydrogen desorption without heating leads to practical engineering hurdles for hydrogen storage and also highlights that both adsorption and desorption isotherms should be considered in the evaluation of modified carbon materials. The results also show that the oxidation of carbon species to facilitate hydrogen spillover is dependent upon both the amount and the nature of surface oxygen species. 
Table 1: Summary of textural properties of as-received and surface modified samples

\begin{tabular}{lcccccc}
\hline $\begin{array}{l}\text { Sample } \\
\text { code }\end{array}$ & $\begin{array}{c}\mathrm{S}_{\mathrm{BET}}{ }^{\mathrm{a}} \\
\left(\mathrm{m}^{2} / \mathrm{g}\right)\end{array}$ & $\begin{array}{c}\mathrm{V}_{\mathrm{N} 2}{ }^{\mathrm{b}} \\
\left(\mathrm{cm}^{3} / \mathrm{g}\right)\end{array}$ & $\begin{array}{c}\mathrm{S}_{\text {micro }}{ }^{\mathrm{c}} \\
\left(\mathrm{m}^{2} / \mathrm{g}\right)\end{array}$ & $\begin{array}{c}\mathrm{V}_{\text {micro }}{ }^{\mathrm{d}} \\
\left(\mathrm{cm}^{3} / \mathrm{g}\right)\end{array}$ & $\begin{array}{c}\mathrm{W}_{\text {ave }}{ }^{\mathrm{e}} \\
(\mathrm{nm})\end{array}$ & $\begin{array}{c}\text { Density } \\
\left(\mathrm{g} / \mathrm{cm}^{3}\right)\end{array}$ \\
\hline $\mathrm{AC}$ & 3145 & 1.35 & 512 & 0.14 & 0.56 & 1.96 \\
$\mathrm{AC}-\mathrm{o}$ & 2720 & 1.13 & 486 & 0.13 & 0.52 & 2.01 \\
5\% Pt-C & 651 & 0.18 & 380 & 0.10 & 0.54 & 2.50 \\
Pt-C/AC-o & 2286 & 0.97 & 445 & 0.12 & 0.52 & 2.20 \\
\hline
\end{tabular}

${ }^{\text {a }}$ BET specific surface area

${ }^{\mathrm{b}}$ Total pore volume; nitrogen used as the adsorbed phase

${ }^{c}$ Specific surface area of micropores

${ }^{\mathrm{d}}$ Micropore volume; $\mathrm{CO}_{2}$ used as the adsorbed phase

${ }^{\mathrm{e}}$ Average pore width estimated from $\mathrm{S}_{\text {micro }}$ and $\mathrm{V}_{\text {micro }}$ by assuming a slit-shaped pore

${ }^{\mathrm{f}}$ Helium density (true density)

Table 2: Surface composition of as-received AC, KOH-modified AC (AC-o) and Pt-C/AC-o at different experiment stages

\begin{tabular}{lccccc}
\hline Sample code & C 1s (\%) & O 1s (\%) & K 2s (\%) & Pt 4f $(\%)$ & O: $C^{c}$ \\
\hline AC & 81.15 & 18.85 & 0 & 0 & 0.23 \\
AC-o & 72.94 & 20.48 & 6.58 & 0 & 0.28 \\
Pt-C/AC (as-received) & 74.70 & 20.88 & 3.84 & 0.58 & 0.28 \\
dPt-C/AC-o $^{\text {a }}$ & 75.04 & 19.97 & 4.58 & 0.40 & 0.27 \\
wPt-C/AC-o $^{\text {b }}$ & 72.65 & 22.23 & 4.68 & 0.44 & 0.30 \\
\hline
\end{tabular}

${ }^{a} \mathrm{Pt}-\mathrm{C} / \mathrm{AC}-\mathrm{o}$ pretreated in dry hydrogen; characterization after $\mathrm{H}_{2}$ adsorption

${ }^{\mathrm{b}} \mathrm{Pt}-\mathrm{C} / \mathrm{AC}-\mathrm{o}$ pretreated in wet hydrogen (see text); characterization after $\mathrm{H}_{2}$ adsorption

${ }^{\mathrm{c}}$ Atomic ratio of oxygen to carbon 

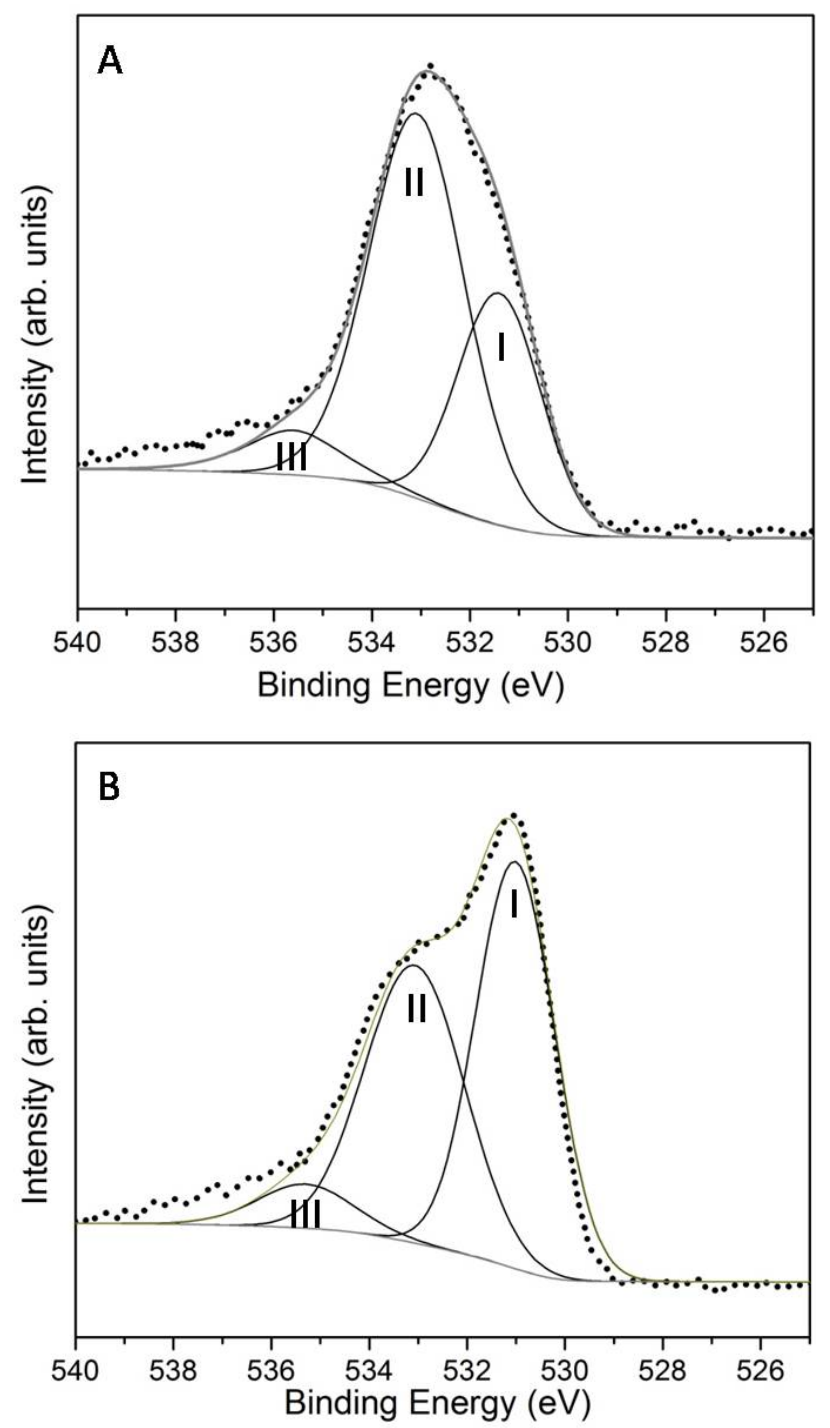

Figure 6: High resolution O 1s XPS spectra (dotted line) and curve fitting (solid line) of (A) AC and (B) AC-0. Peak I (531.1$531.6 \mathrm{eV})$ is assigned to oxygen in carbonyl or quinone groups. ${ }^{18,19}$ Peak II $(\sim 533.1 \mathrm{eV})$ is assigned to oxygen atoms in esters, carboxylic anhydrides and oxygen atoms in hydroxyls or ethers. ${ }^{18,} 20$ Peak III indicates adsorbed water or oxygen. ${ }^{19}$ 


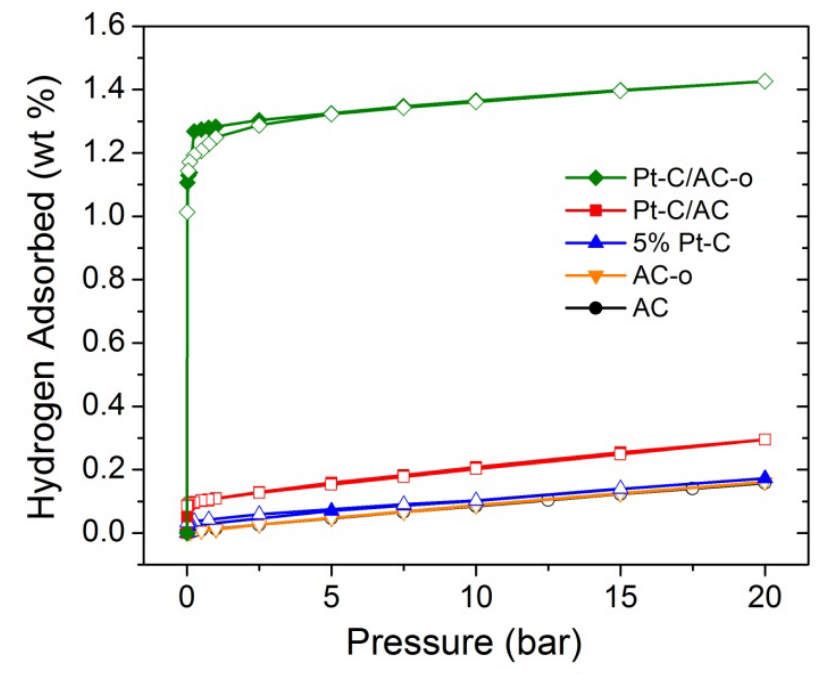

Figure 7: Effect of carbon oxidation in Set-up 1: Hydrogen isotherms $\left(25{ }^{\circ} \mathrm{C}\right)$ of $\mathrm{AC}, \mathrm{AC}-0,5 \% \mathrm{Pt}-\mathrm{C}$, and Pt-C/AC-0. The isotherm of Pt-C/AC-o is indicative of hydrogen spillover, in that the hydrogen uptake of the physical mixture of the Pt-C catalyst and the secondary AC-o support exceed that expected if their individual contributions were additive. Isotherm of AC and AC-o are overlapping with each other. Solid signs are representing adsorption, hollow signs are for desorption. Lines are used to lead the eyes.

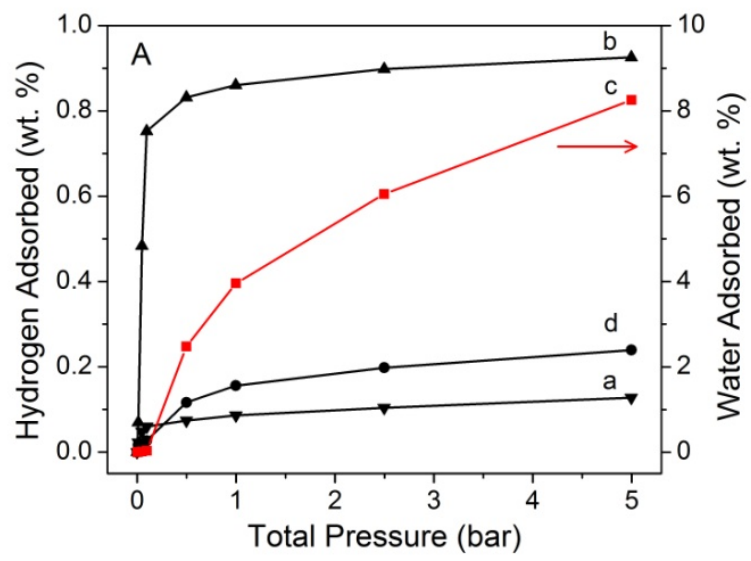

Figure 8: Isotherms of Pt-C/AC-o (25 oC) obtained in Set-up 2. (a) H2 adsorption after dry pretreatment, dPt-C/AC-0; (b) H2 adsorption after wet pretreatment (see text), wPt-C/AC-o; (c) $\mathrm{H} 2 \mathrm{O}$ adsorption after wet pretreatment (x-axis shows the total pressure of He/H2O mixture); and (d) H2 adsorption following evacuation after $\mathrm{H} 2 \mathrm{O}$ adsorption for (c). Data is plotted as total pressure of the system. 

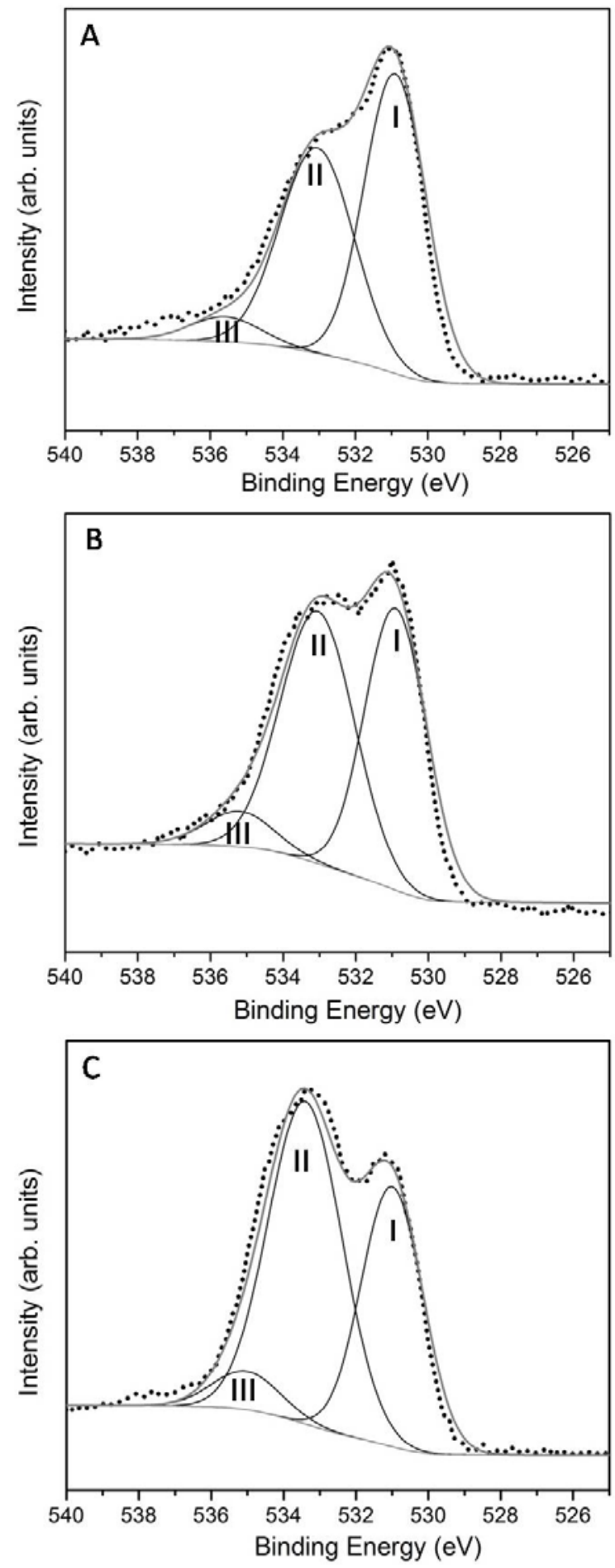

Figure 9: High resolution O 1s XPS spectra (dotted line) and curve fitting (solid line) of (a) as-synthesized Pt-C/AC-o, (b) after dry pretreatment and $\mathrm{H} 2$ adsorption, dPt-C/AC; and (c) after wet pretreatment and $\mathrm{H} 2$ adsorption, wPt-C/AC. Peak II increases in two post-adsorption samples. The area ratio of peak II to peak I for the three samples is $0.82,1.07$ and 1.49 , respectively. 


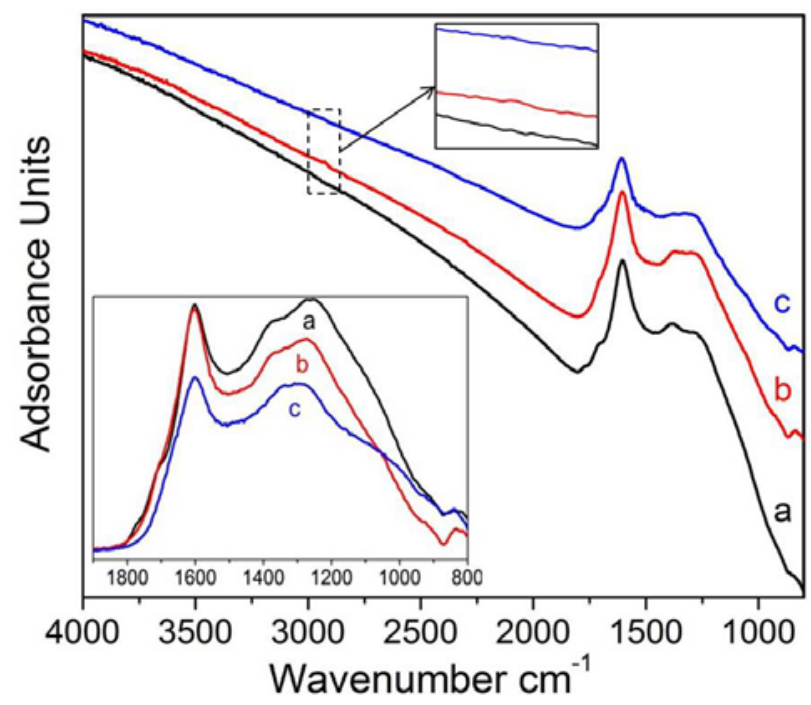

Figure 10: FTIR spectra of (a) as-synthesized Pt-C/AC-o, (b) after dry pretreatment and H2 adsorption, dPt-C/AC; and (c) after wet pretreatment and $\mathrm{H} 2$ adsorption, wPt-C/AC. All spectra were collected at $50 \mathrm{oC}$. Inset is the spectra after subtracting of background.
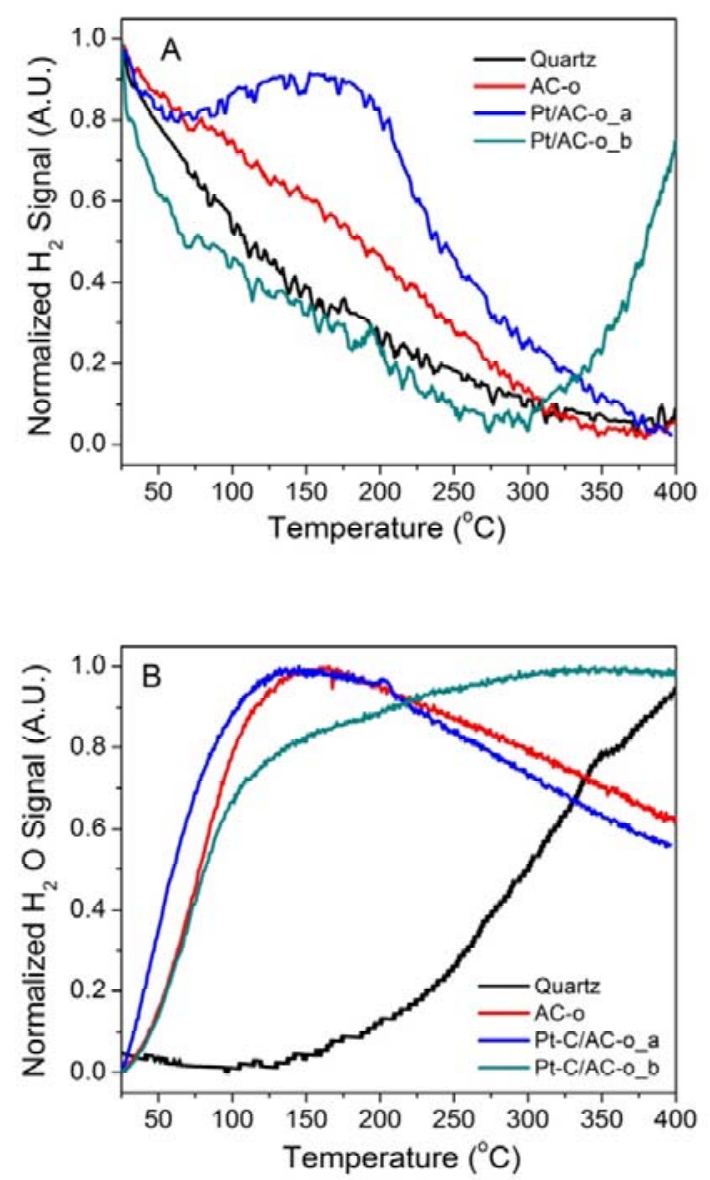

Hydrogen/Water Desorption Temperatures from Oxygen-Modified Carbon-Based Spillover Materials.

Overview. The following section outlines experiments that are intended to clarify whether the $\mathrm{H}_{2}$ adsorption reported in the previous section desorb from the oxidized carbons as $\mathrm{H}_{2}$ or $\mathrm{H}_{2} \mathrm{O}$. Previous literature gives contradictory predictions on this: Yang et al. ${ }^{21}$ indicate semiquinone groups will reversibly adsorbdesorb spilt-over hydrogen, whereas a simulation by Psofogiannakis et al. ${ }^{22}$ indicates spilt-over hydrogen bound to oxygen functional groups will desorb more favorably as water. The latter has obvious negative consequences for the reversibility of hydrogen storage in oxygen-modified carbon materials. The controversy exhibits the importance of the desorption species of oxygen-modified carbon materials. We anticipate the desorption species (whether $\mathrm{H}_{2}$ or $\mathrm{H}_{2} \mathrm{O}$ ) will depend not only on the nature of the oxygen functional groups, but

Figure 11: TPD spectra of quartz (used as background signal test), oxidized AC (AC-o) and Pt-doped AC-o (PtC/AC-o). (A) Normalized H2 signal; (B) Normalized H2O signal. Pt-C/AC-o_a and Pt-C/AC-o_b designate samples from different batches. 
also the oxygen groups populated by spilled over hydrogen, which would be dependent upon adsorption temperature. Here, we use temperature programmed desorption (TPD), which has been used extensively for the study of oxygen functional groups ${ }^{19,23}$ and spilt-over hydrogen $^{24,25}$. In this section, TPD is employed to identify the desorbed species from various oxygenmodified carbon materials, with an emphasis on $\mathrm{H}_{2}$ and $\mathrm{H}_{2} \mathrm{O}$. Experiments are on-going, and the intent is to submit this preliminary data as a peer-reviewed publication once complete.

Results. TPD of samples after the adsorption-desorption isotherm with heating from adsorption temperature (TPD-Method 1) are compared in Figure 11. In all cases, the $\mathrm{H}_{2}$ MS signal decreases slightly as $\mathrm{H}_{2}$ is removed from the reaction chamber after sorption. TPD of AC-o

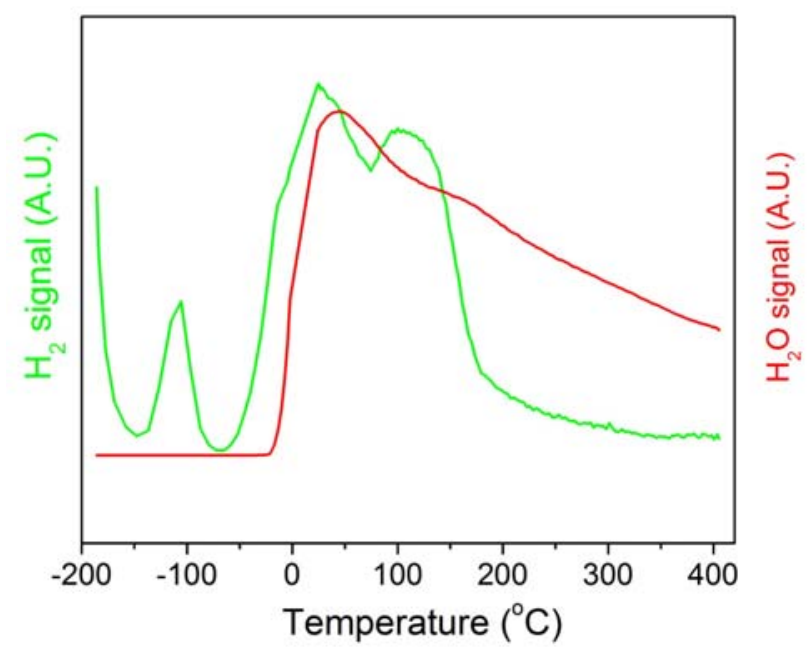

Figure 12: TPD spectra of Pt-C/AC-o_c using TPD-Method 2 (quenching to $77 \mathrm{~K}$ prior to heating). Green line represents $\mathrm{H}_{2}$ signal, red line represents $\mathrm{H}_{2} \mathrm{O}$ signal. has only a slight inflection in $\mathrm{H}_{2}$ signal above the quartz background, whereas two oxidized carbon samples (Pt/AC-o_a vs. _b; prepared from different batches) have more pronounced $\mathrm{H}_{2}$ signals in the TPD. For sample ' $\mathrm{a}$ ', $\mathrm{H}_{2}$ evolution is shown $150-200{ }^{\circ} \mathrm{C}$, whereas no $\mathrm{H}_{2}$ evolution is observed in sample ' $\mathrm{b}$ '. In sample ' $\mathrm{b}$ ' $\mathrm{H}_{2}$ begins to desorb at $300{ }^{\circ} \mathrm{C} . \mathrm{H}_{2} \mathrm{O}$ evolution from the two samples also differ, with 'a' showing similar behavior to that of the AC-o, and ' $b$ ' showing an increase in $\mathrm{H}_{2} \mathrm{O}$ evolution with temperature. The results indicate that the surface chemistry of samples ' $a$ ' and ' $b$ ' differ, and suggest the groups on ' $b$ ' are more prone to dehydration. The literature suggests physisorbed water will evolve at $\sim 150{ }^{\circ} \mathrm{C}^{26}$ and $\mathrm{H}_{2} \mathrm{O}$ evolving at temperatures greater than $300{ }^{\circ} \mathrm{C}$ suggest dehydration of oxygen functional groups on the carbon surface, such as phenols. ${ }^{26,27}$ When samples are quenched to 77K prior to TPD (Figure 12, Method TPD-2), the signals above room temperature are similar to those of ' $\mathrm{a}$ ' in Figure 11. Evidence for physisorption is shown with $\mathrm{H}_{2}$ evolution at temperatures below ambient, even though sample is cooled in vacuum.

\section{High-Pressure in situ Analytical Techniques.}

Overview. The initial objective of the project was to understand the active adsorption sites in carbon materials that have been activated with nanocatalysts, and use this knowledge to enhance synergistic effects that create new adsorption sites and activate the carbon nanomaterials for adsorption in the DOE target temperature and pressure range. To understand, identify, and optimize specific adsorption sites, in situ high-pressure analytical techniques were to be used to fully characterize these sites at the pressures of interest. Both RBMA and SWNT were selected for these studies. RBMA had behavior at low pressure characteristic of hydrogenated tetrahedral amorphous carbon, while SWNT had been theoretically predicted to partially rehybridize to $\mathrm{sp}^{3}$ carbon upon the application of high pressure [22] and/or resulting from hydrogen chemisorption [23]. Cheng, et al., showed through molecular dynamics simulations that SWNTs were prone to distortion upon exposure to hydrogen which resulted in an increased adsorption energy and stretching of the molecular hydrogen bond [24]. In these studies, a Pt spillover catalyst was added to the surface of the SWNT via incipent wetness doping with the intent to dissociate molecular $\mathrm{H}_{2}$ to initiate hydrogenation of the surface of the $\mathrm{sp}^{2}$-hybridized SWNT. The $\mathrm{Pt} / \mathrm{SWNT}$ was treated in $\mathrm{H}_{2}$ in situ in a custom-built reactor, as described above. 


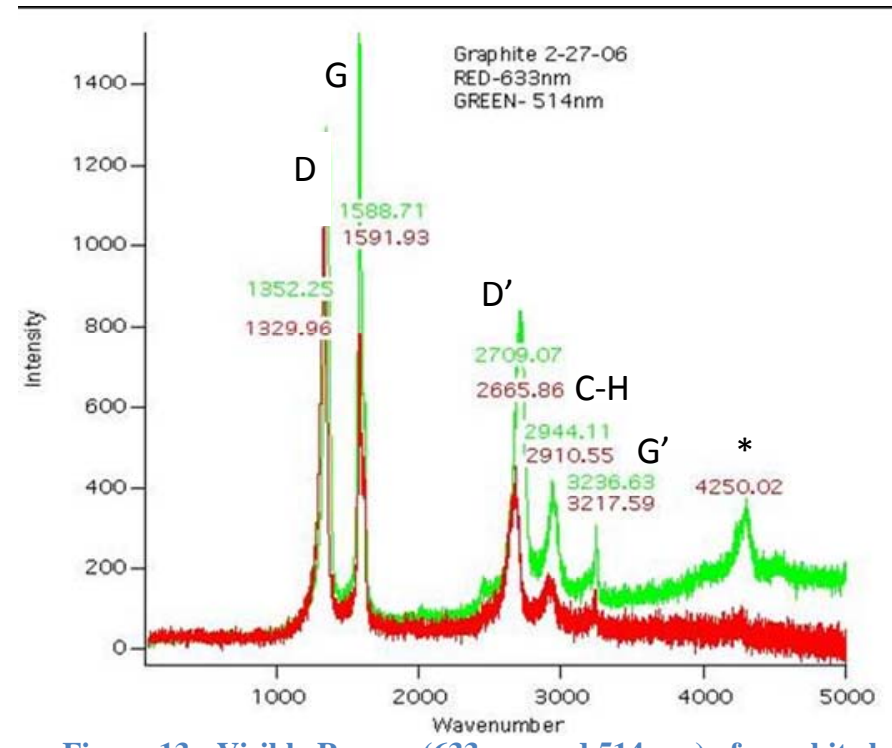

Figure 13: Visible Raman (633 $\mathrm{nm}$ and $514 \mathrm{~nm}$ ) of graphite ball milled in cyclohexene at 1 bar. The origin of the peak at 4250 cm-1 (514 nm, *) is being further explored. Ball milled carbons (and RBMAs) were used to establish procedures for Multiwavelength Raman methods.
RBMA Studies. RBMAs were used to establish characterization procedures for hydrogenated tetrahedral amorphous carbons, as RBMAs were previously shown ${ }^{7}$ to have regions of suspected $\mathrm{sp}^{2}$ $\mathrm{sp}^{3}$ phase transition. Therefore these materials provided a means to establish methods to study the carbon transitions that may occur during interaction with hydrogen. Figure 13 shows the Raman spectra of ball milled graphite (RBMG, a variation on RBMA) at two different wavelengths in the visible region, $514 \mathrm{~nm}$ and $633 \mathrm{~nm}$. At $633 \mathrm{~nm}$, Raman spectroscopy of RBMG includes the characteristic carbon $\mathrm{D}$ and $\mathrm{G}$ peaks at $1330 \mathrm{~cm}^{-1}$ and $1590 \mathrm{~cm}^{-1}$, respectively. Also shown are secondary reflections for D (D' at $2666 \mathrm{~cm}^{-1}$ ), secondary reflections for $\mathrm{G}\left(\mathrm{G}^{\prime}\right.$ at $\left.3218 \mathrm{~cm}^{-1}\right)$, and a peak attributed to carbon-hydrogen stretching $\left(2910 \mathrm{~cm}^{-1}\right)$. At 633 $\mathrm{nm}$, the $1330 \mathrm{~cm}^{-1} \mathrm{D}$ peak is attributed to $\mathrm{sp}^{2}$ defects rather than diamond, due to the broadness of the peak and $\sim 50$-fold greater intensity of $\mathrm{sp}^{2}$ carbon relative to $\mathrm{sp}^{3}$ carbon. An additional prominent feature in the Raman spectra of RBMG is a split G peak with an unusual high-energy shoulder, which can be resolved to two peaks at $1590 \mathrm{~cm}^{-1}$ and $1620 \mathrm{~cm}^{-1}$. The strength of the $1620 \mathrm{~cm}^{-1}$ peak is related to the strong intensity of the disordered ' $D$ ' peak at $1350 \mathrm{~cm}^{-1}{ }^{28}$ This peak at $1620 \mathrm{~cm}^{-1}$ was also observed in RBMG milled in highpressure hydrogen, and attributed to $\mathrm{sp}^{2}$-hybridized carbon defects introduced during ball milling. ${ }^{29}$ At $514 \mathrm{~nm}$,
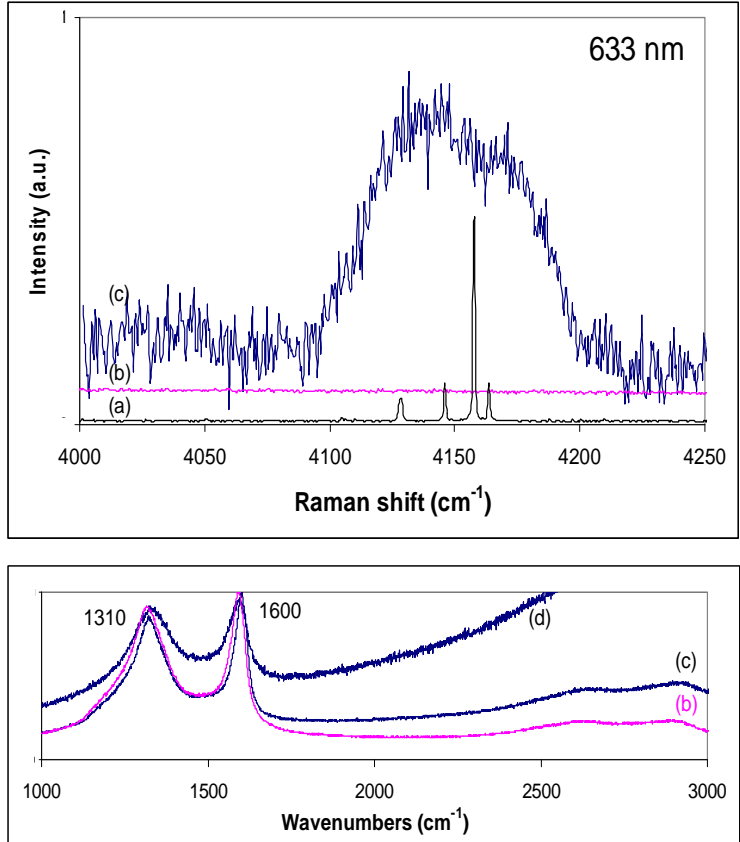
the $\mathrm{D}$ and $\mathrm{G}$ peaks are shifted to $1352 \mathrm{~cm}^{-1}$ and $1589 \mathrm{~cm}^{-1}$, respectively. This is expected for MW Raman spectroscopy of disordered carbon materials. A new feature in the spectra at $514 \mathrm{~nm}$ is a peak at $4250 \mathrm{~cm}^{-1}$ which is in the region for molecular hydrogen stretching. The UV Raman of this sample (data shown in ${ }^{30}$ ) suggests a very weak indication of a $\mathrm{T}$ (tetrahedral) peak at around $950 \mathrm{~cm}^{-1}$, which is due to carbon-carbon $\mathrm{sp}^{3}$ vibrations in disordered materials. A weak signal at $4400 \mathrm{~cm}^{-1}$ is also found in UV.

The feature above $4200 \mathrm{~cm}^{-1}$ was of particular interest. In conjunction with ambient temperature hydrogen evolution reported elsewhere, ${ }^{7}$ the Raman spectroscopy provided supporting evidence for an unusual hydrogen interaction within the material. Molecular hydrogen has a characteristic strong Raman vibron centered at $4160 \mathrm{~cm}^{-1}$ (Figure 14a), one of several Q branch lines $\left(Q_{1}(J)(\Delta v=1 ; \Delta J=0 ; J=0,1,2,3){ }^{31}\right.$, 32 The vibron is perturbed by intermolecular interactions: Physisorption of hydrogen to nanocarbons at $85 \mathrm{~K}$ and 4-8

Figure 14: Raman spectra of (a) gaseous $\mathrm{H}_{2}$ at $130 \mathrm{~atm}$, (b) the anthracite coal precursor, and the ball milled sample (c) one year and (d) one week after preparation. The upper portion of the graph presents the region of interest to $\mathrm{H}_{2}$, while the lower portion of the graph presents the usual carbon vibrations (D at $1310, \mathrm{G}$ at $1600 \mathrm{~cm}^{-1}$ ). 
atmosphere of hydrogen pressure shifts it by $1-3 \mathrm{~cm}^{-1}{ }^{33}$ Similarly, physisorption of hydrogen on amorphous carbon at $150 \mathrm{~K}$ and hydrogen pressures up to 64 bar perturbs it by $1-2 \mathrm{~cm}^{-1} .{ }^{34}$ The energetics of the shift appear to depend on the nature of the carbon binding sites, as no consistent trends are found in the above papers. The $\mathrm{H}_{2}$ is more affected as hydrogen becomes incorporated or caged within a solid: Hydrogen present in silicon dislocations ('platelets') is perturbed by $\sim 4 \mathrm{~cm}^{-1}$, whereas $\mathrm{H}_{2}$ incorporated at tetrahedral interstitial sites within crystalline silicon is shifted more than $500 \mathrm{~cm}^{-1} .{ }^{35}$ The above studies were performed either at high-pressure and cryogenic temperatures, ${ }^{33,34}$ or after treatment in a hydrogen plasma. ${ }^{35}$ The high wavenumber Raman feature after reactive milling (Figure 14c) is in close proximity to that observed for molecular $\mathrm{H}_{2}$ (Figure 14a). This feature in the range of $4125-4166 \mathrm{~cm}^{-1}$ was observed only for milled materials which also exhibited low temperature hydrogen evolution via temperature-programmed mass spectroscopy. It disappeared after heating with the laser used for the Raman analysis for a period of time. It needed to be differentiated from high order peaks for graphite that occur at $\sim 4300 \mathrm{~cm}^{-1}$, and although higher order peaks can shift based on carbon structure, higher order peaks for the anthracite carbon precursor were not observed (Figure 14b) despite similarities in the spectra at lower energy (Figure 14, lower portion). It should also be noted that these Raman features are apparent only in aged samples (i.e. one year after preparation), as freshly prepared samples have a high degree of photoluminescence. Photoluminescence is associated with the hydrogen content of tetrahedral amorphous carbons $;{ }^{36}$ here, the photoluminescence decreases with time, indicating that the hydrogen content of the material decreases with time. Work to verify these feature has become the subject of a project recently funded (2009) DOE Basic Energy Science, due in a large part to the initial work performed on this project. When/if conclusively shown to be due to $\mathrm{H}_{2}$, when measured at room temperature in ambient air, such a feature would indicate molecular $\mathrm{H}_{2}$ was trapped during synthesis, and slowly diffusing out of a metastable material. Such a finding would be of particular interest to the hydrogen storage field, and had not previously been observed.

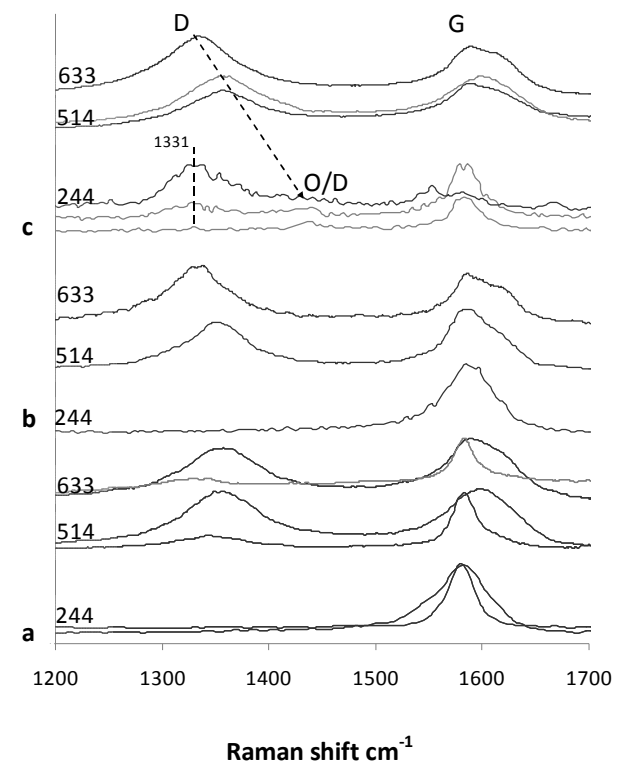

Figure 16: MWR of RBMA at various stages of preparation (a-c are sequential stages) was used to 'validate' carbon-hydrogen interactions. Numbers shown indicate the Raman excitation frequency.

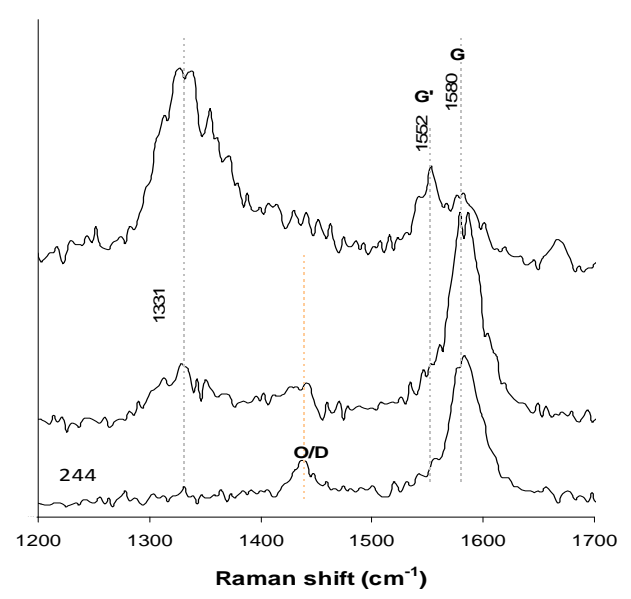

Figure 15: Variation of the RBMA carbon features in UV Raman shows unusual G-peak splitting and a suspected diamond peak at $1331 \mathrm{~cm}^{-1}$ 
MWR Studies II: Probing Carbon-Hydrogen Interactions with Excitation, and Use to Deduce Synthesis. There was also interest in probing the nature of the carbon material that could give rise to unusual carbon-hydrogen interactions. This work further illustrates our use of MWR, and as it was enabled through this project, will be submitted with reference to this funding in Summer 2010. Shown in Figure 16 are the Raman spectra of RBMA at various stages of synthesis. After a thermal anneal of RBMA, Raman spectra Figure 16a) show the characteristic $\mathrm{D}$ and $\mathrm{G}$ peaks with visible excitation (both 633 and $514 \mathrm{~nm}$ ). The D peak and $\mathrm{G}$ peak positions varied with sampling location, as shown, from $1332-1360 \mathrm{~cm}^{-1}$ for $\mathrm{D}$ and $1580-1600 \mathrm{~cm}^{-1}$ for G. Despite heterogeneities, the narrow $G$ peak in certain sampling locations reflects the high graphitic order of certain regions, consistent with the TEM observation of this sample (data not shown). UV excitation with $244 \mathrm{~nm}$ indicates the characteristic $\mathrm{G}$ peak (ranging from $1580-1590 \mathrm{~cm}^{-1}$ based on sampling location). The disappearance of the D peak in UV $244 \mathrm{~nm}$ Raman is as expected for graphitic materials. After a second stage of treatment, Raman spectra (Figure 16b) show the characteristic D and G peaks in visible excitation (514 and $633 \mathrm{~nm}$ ). The G peak in both 514 and $633 \mathrm{~nm}$ excitation appears asymmetric, with a high-frequency shoulder at $\sim 1620 \mathrm{~cm}^{-1}$; a feature attributed to either polymeric chain-like $\mathrm{sp}^{2}$ carbons and/or nanographene ribbons. After a third stage in synthesis, visible Raman $(514$ and $633 \mathrm{~nm}$ ) show the characteristic D and G peaks. UV Raman (244 nm, Figure 16c) spectra has the G (1580-1589 $\mathrm{cm}^{-1}$ ) peak in the visible spectra, and the D peak (expected at $1450 \mathrm{~cm}^{-1}$ in UV) has decreased. Select samples ( 3 out of 5 sampling points collected) have evidence for a peak at $1331 \mathrm{~cm}^{-1}$; UV spectra for select sampling locations are shown in more detail in Figure 15. The sampling location with the greatest evidence for a feature at $1331 \mathrm{~cm}^{-1}$ also showed evidence for splitting of the $\mathrm{G}$ peak to lower frequencies, to $1552 \mathrm{~cm}^{-1}$ and $1580 \mathrm{~cm}^{-1}$. G-peak splitting to lower frequency at $633 \mathrm{~nm}$ excitation has been found in theoretical modeling of tetrahedral amorphous carbons; the splitting arises due to the limited number of $\mathrm{sp}^{2}$ atoms in the model structure. ${ }^{37}$ RBMA samples that were demineralized prior to the ball milling and chemical treatment sequence showed no evidence for a feature at $1331 \mathrm{~cm}^{-1}$.

Exposing RBMA to high-pressure $\mathrm{H}_{2}$ in situ indicated changes in structure (Figure 17), as evidenced by changes in the characteristic carbon features in Raman upon exposure to 2000 psi $\mathrm{H}_{2}$. The D:G ratio changes slightly upon $\mathrm{H}_{2}$ exposure, and there is approximately a $\sim 50 \%$ reduction in the breadth of the $\mathrm{D}$ peak upon $\mathrm{H}_{2}$ exposure. There is a more distinct change in the region of overlap between the $\mathrm{D}$ and $G$ peaks; this overlap of the $D$ and $G$ peak is characteristic of "diamond-like" (i.e. $\mathrm{sp}^{3}$ hybridized carbon, mixed with $\mathrm{sp}^{2}$ hybridized carbon, both of amorphous character). There is a peak at $3080 \mathrm{~cm}^{-1}$ that appears only upon $\mathrm{H}_{2}$ exposure; the peak is reproducible and in the range expected for a $\mathrm{C}-\mathrm{H}$ bond.

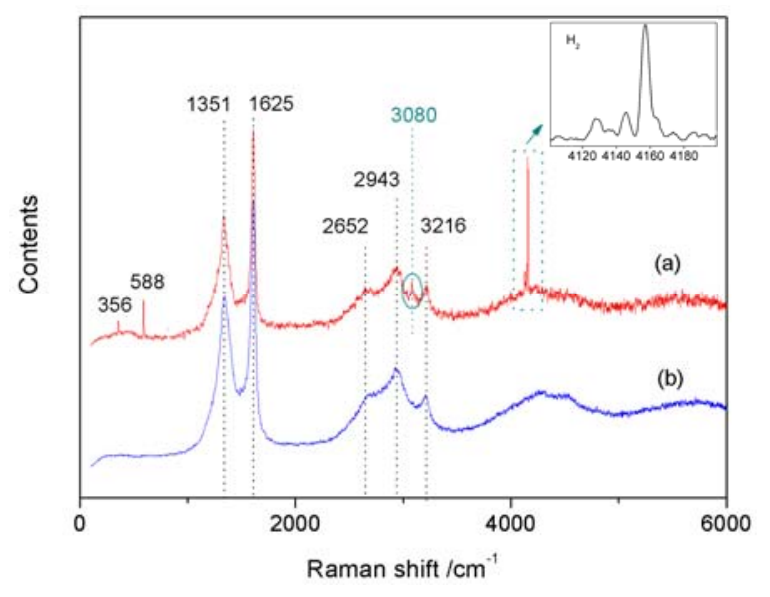

Figure 17: High pressure in situ Raman characterization of RBMA: (a) in $2000 \mathrm{psi} \mathrm{H}_{2}$, (b) in air. Referenced in the text are the $D$ peak at $1351 \mathrm{~cm}^{-1}$; G peak at $1625 \mathrm{~cm}^{-1}$, both are characteristic for carbon materials. A peak at $3080 \mathrm{~cm}^{-1}$ is suggestive of a carbon-hydrogen bond. 
Spillover to Carbon Nanotubes I (SWNT).

SWNT provide an ideal carbon structure with well-characterized properties. SWNT were selected to determine whether hydrogenation via spillover would lead to appreciable changes in in situ high-pressure Raman spectroscopy, towards the original objectives of this work. Gravimetric hydrogen adsorption for $1 \%$ $\mathrm{Pt} / \mathrm{SWCNT}$ after pretreatment in flowing $\mathrm{H}_{2}$ is typical of metaldoped carbons (Figure 18). There is a rapid uptake at low pressures as the supported catalyst becomes saturated with hydrogen. At moderate pressures ( $\mathrm{P}>\sim 1$ bar), the uptake of the material is due primarily to the carbon. Hysteresis is observed between adsorption and desorption, and this is attributed to retention of hydrogen by the supported metal. Platinum will retain atomic hydrogen at its surface upon reduction of hydrogen; the hydrogen will be desorbed only as the temperature is increased.

High-pressure in situ Raman data for a $1 \% \mathrm{Pt} / \mathrm{SWCNT}$ series were

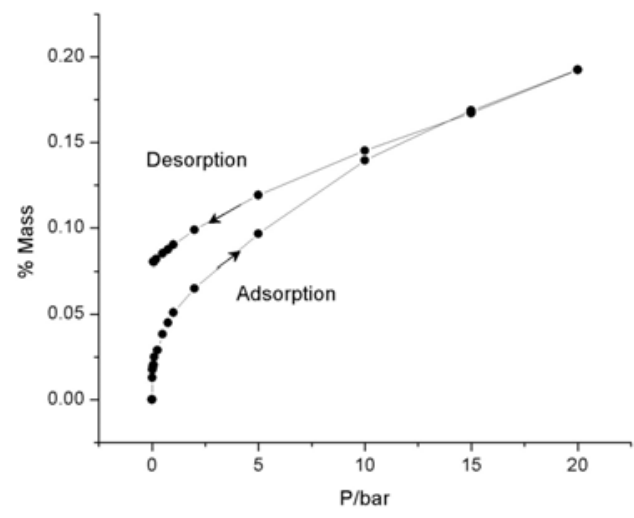

Figure 18: Gravimetric adsorption on $1 \%$ $\mathrm{Pt} / \mathrm{SWNT}$ at $300 \mathrm{~K}$ is typical of hydrogen spillover, and exhibits appreciable adsorptiondesorption hysteresis. collected before and after the $\mathrm{H}_{2}$ adsorption isotherm (Figure 19).

Comparing the (1) as-synthesized $1 \% \mathrm{Pt} / \mathrm{SWNT}$ to (2) the sample after the $\mathrm{H}_{2}$ isotherm shows an increase in the relative intensity of the second-order Raman feature after $\mathrm{H}_{2}$ exposure. Subsequent steps show little change in Raman features. Following these results, a blank experiment replaced $\mathrm{H}_{2}$ with $\mathrm{He}$ in the $200{ }^{\circ} \mathrm{C}$ reduction of (2) [while still exposing to a 20 bar $\mathrm{H}_{2}$ isotherm following the $200{ }^{\circ} \mathrm{C}$ treatment]. A shift in the low-frequency radial breathing modes (RBMs) of the SWNT sample is observed after the $200{ }^{\circ} \mathrm{C}$ treatment and adsorption, regardless of whether $\mathrm{He}$ or $\mathrm{H}_{2}$ is used in (Figure 20b-c). As RBMs are inversely proportional to the diameter of the SWNT, the shift superficially suggests a change in diameter with heating, but more analysis is needed to confirm this statement. There is a slight addition of a 'shoulder' in the RBMs for the sample taken at high

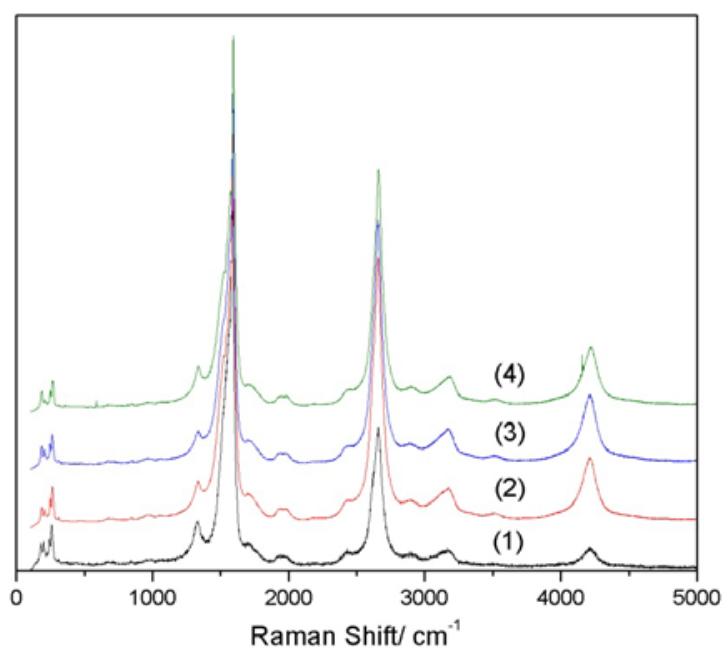

pressure (Figure 20d).
Figure 19: Raman spectroscopy for a 1\% Pt/SWNT series at various stages of synthesis and hydrogen exposure: (1) after $1 \%$ platinum doping of SWNT; (2) following reduction at $200{ }^{\circ} \mathrm{C}$ and a 20 bar $\mathrm{H}_{2}$ isotherm; (c) following a second $200{ }^{\circ} \mathrm{C}$ reduction in $\mathrm{H}_{2}$ and transfer in an inert atmosphere, and (d) exposure of (c) to 100 bar $\mathrm{H}_{2}$ in situ in the capillary tube. All Raman data were collected in a capillary tube; (a-b) were collected in air; (c) in Argon; and (d) in high-pressure $\mathbf{H}_{2}$. 

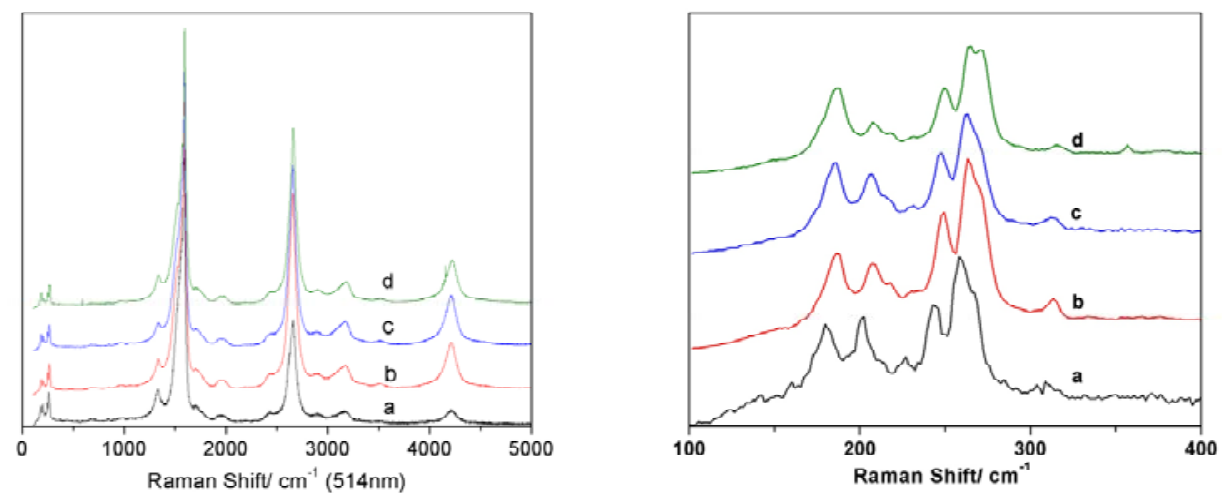

Figure 20: Raman Spectroscopy of 1\% Pt/SWNT: (a) as-synthesized; (b) following exposure to $\mathrm{H}_{2}$ at $200{ }^{\circ} \mathrm{C}$ and 1 bar, then $25{ }^{\circ} \mathrm{C}$ and 20 bar; (c) replacing $\mathrm{H}_{2}$ with $\mathrm{He}$ during the $200{ }^{\circ} \mathrm{C}$ exposure, and (d) exposure of (b) to 100 bar $\mathrm{H}_{2}$ in situ on the Raman spectrometer.

The effect of temperature and surrounding environment on the Raman spectra of carbon nanomaterials was then studied by varying temperature of gas exposure. SWNT (as received) were charged with high pressure (100 bar) $\mathrm{H}_{2}$ in a capillary. The SWNT in 100 bar $\mathrm{H}_{2}$ was heated at $400^{\circ} \mathrm{C}$ for $15 \mathrm{hrs}$. After cooling back to room temperature, Raman data were collected. This procedure was repeated at $500^{\circ} \mathrm{C}, 600^{\circ} \mathrm{C}$, and $700^{\circ} \mathrm{C}$. Data were collected sequentially, with increasing temperature, on the same SWNT sample. The Raman frequency of the RBMs shifts to lower wavenumbers with increased temperatures (Figure 21), which agrees with the results of Zhang et al. ${ }^{38}$ With heating, transverse mode peaks $\left(1500-1600 \mathrm{~cm}^{-1}\right)$ also begin to appear (Figure 22, left). The transverse modes are characteristics of the spectra from different nanotubes geometries. ${ }^{39}$ At lower laser power $(633 \mathrm{~nm})$, no temperature dependence was observed (Figure 22 , right). Similar, but less pronounced, effects were observed when the SWNT were heated in 100 bar He (data not shown).

Summary/Action of the High-Pressure In Situ Studies. At the onset of this project, in situ characterization of carbon-hydrogen materials was intended to be a primary tool to characterize hydrogen spillover in order to direct synthesis. However, the above results were extremely subtle, even for the 'ideal' SWNT case and for materials that had been shown to have dramatic changes in $\mathrm{C}-\mathrm{H}$ content. It seemed that to detect changes arising due to factors within similar carbon materials (e.g. pore structure, morphology, etc.) would lead to even more subtle changes. Such subtleties seemed unlikely to lead to better design of hydrogen storage materials a priori. Thus, efforts were redirected at the conclusion of the above studies. This decision should perhaps be revisited in future work in light of the increased hydrogen uptake for the oxidized AC samples in the previous section. One peer-reviewed paper has been published on this section of the project, ${ }^{40}$ and two are in progress. ${ }^{11,41}$

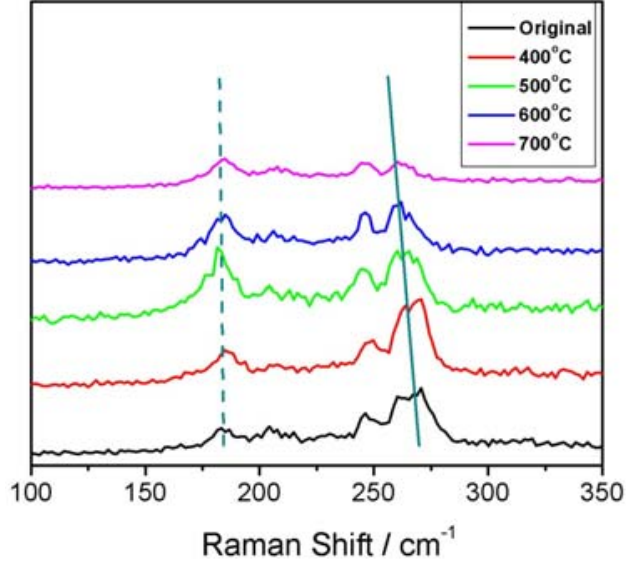

Figure 21: Radial breathing mode (RBM) of SWCNTs heated at different temperatures in high pressure $\mathrm{H}_{2}$ atmosphere $\left(\mathrm{E}_{\text {laser }}=2.41 \mathrm{eV}\right)$. 

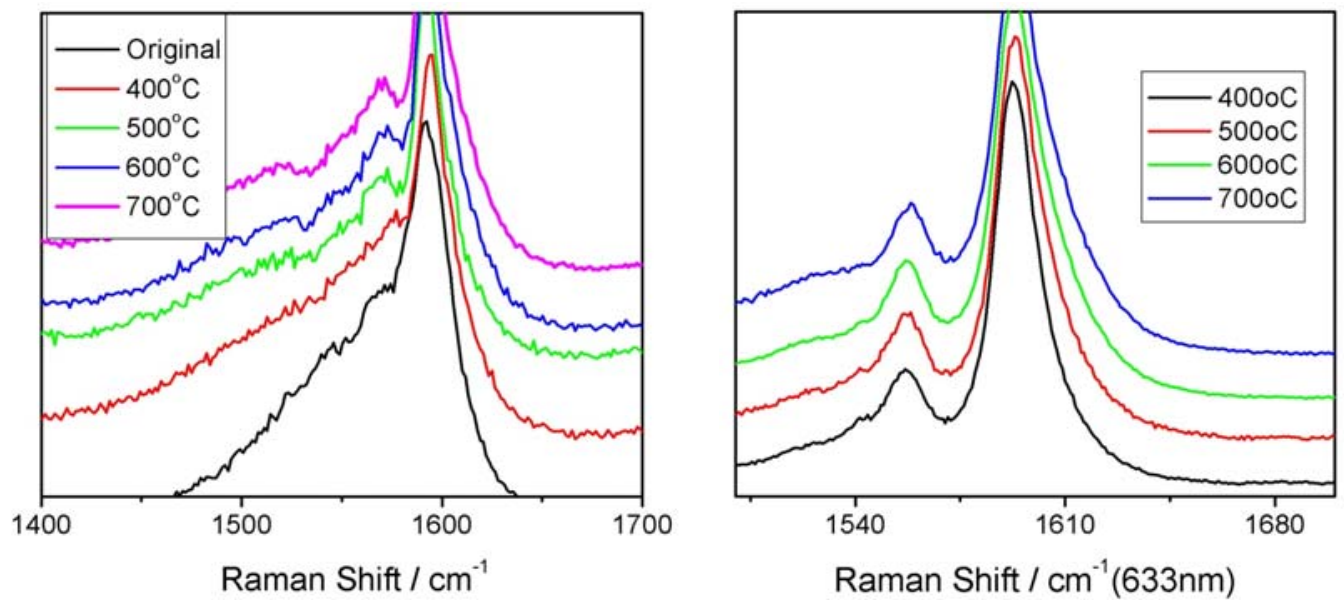

Figure 22: Transverse modes of SWCNTs showed temperature dependence with a Raman excitation of $514 \mathrm{~nm}$ (left), but not at $633 \mathrm{~nm}$ (right). SWNT is heated in 100 bar $\mathrm{H}_{2}$ at the indicated temperatures. All data is collected after cooling back to room temperature.

\section{Other Peer-reviewed Publications Resulting from this Work.}

Low Pressure Hydrogen Spillover. This work was presented at the 2008 Annual Meeting of the American Institute of Chemical Engineers. The primary experimental details of this work are summarized in the Methods section. Set-up 1 was used. More specifically, this work included a reduction in flowing $\mathrm{H}_{2}(50 \mathrm{~mL} / \mathrm{min}$, $\left.250^{\circ} \mathrm{C}, 6 \mathrm{~h}\right)$ followed by a vacuum degas $\left(380^{\circ} \mathrm{C}, 8 \mathrm{hr}\right)$. When samples were cooled from the degas treatment to room temperature, the weight increase of certain samples significantly exceeded that expected based on buoyancy considerations. (Full consideration of buoyancy is based on a quartz blank of equal volume, and outlined in ${ }^{42}$ ). The uptake was attributed to migration of hydrogen $a b$ sorbed in the stainless steel reactor (N.B. embrittlement of stainless steel by $\mathrm{H}_{2}$ is due to significant absorption) to the sample. This migration suggests many isotherms conducted in stainless steel reactors may under-report hydrogen uptake, particularly when the mechanism for hydrogen uptake is either chemisorption or hydrogen spillover. Results from this study are summarized in Table 3. An initial draft of this manuscript is written, ${ }^{43}$ but we intend to supplement this draft manuscript with mass spectroscopy to verify the uptake is due to $\mathrm{H}_{2}$. Submission is expected in late 2010, as Li finished her Ph.D. thesis. 
Table 3: Summary of Low-Pressure (Vacuum) Hydrogen Uptake Attributed to Hydrogen Spillover

\begin{tabular}{|c|c|c|c|c|c|c|c|}
\hline Sample & $\begin{array}{c}\mathrm{W}_{2} \\
(380 \mathrm{oC}) / \mathrm{mg}\end{array}$ & $\begin{array}{c}\mathrm{W}_{1} \\
(25 \mathrm{oC}) / \mathrm{mg}\end{array}$ & $\mathrm{m}_{\mathrm{s}}{ }^{\mathrm{o}}(\mathrm{mg})$ & $\mathrm{m}_{\text {ads }}(\mathrm{mg})$ & $\begin{array}{c}\mathrm{H} 2 \text { adsorbed } \\
/ \mathrm{wt} \%\end{array}$ & $\begin{array}{c}\text { Metal } \\
\text { content }(\mathrm{g} / \mathrm{g})\end{array}$ & $\begin{array}{c}\mathrm{H}: \mathrm{M} \text { ratio } \\
(\mathrm{mol} / \mathrm{mol})\end{array}$ \\
\hline Quartz & 68.9091 & 69.4706 & 69.4706 & 0.00 & $0.00 \%$ & 0 & 0.00 \\
\hline $\begin{array}{c}\text { Activated } \\
\text { Carbon }\end{array}$ & 48.9427 & 49.4867 & 49.5042 & -0.02 & $-0.04 \%$ & 0 & $\mathrm{NA}$ \\
\hline $\begin{array}{c}5 \% \text { Pt- } \\
\text { C+AC+carb } \\
\text { on bridge } \\
(1: 8: 1)\end{array}$ & 51.2357 & 51.9022 & 51.7972 & 0.10 & $0.20 \%$ & $0.50 \%$ & 79.10 \\
\hline $\begin{array}{c}5 \% \text { Pd- } \\
\text { C+AC+carb } \\
\text { on bridge } \\
(1: 8: 1)\end{array}$ & 54.2781 & 54.899 & 54.8396 & 0.06 & $0.11 \%$ & $0.50 \%$ & 23.05 \\
\hline $5 \%$ Pd-C & 49.7549 & 50.7636 & 50.3164 & 0.45 & $0.88 \%$ & $5 \%$ & 18.91 \\
\hline
\end{tabular}

Etched Graphite Nanofibers: Nanoporous carbons used in initial stages of this work were GNFs and EGNFs, with the intention of selectively tuning the graphitic order (of GNF) and pore size (of EGNF) to study the effect of these parameters on hydrogen spillover. Unfortunately, exfoliation of GNF to EGNF was not always straightforward, with graphitic order and synthesis conditions largely determining the efficacy of exfoliation. At times, the exfoliation process led to etching rather than true exfoliation ${ }^{1}$ (see, e.g. Figure 23). For this reason, GNF and EGNF were later substituted with other carbon materials. However, the results of the EGNF synthesis work were reported in a peer-reviewed publication, ${ }^{1}$ which emphasized difference in carbon morphology when true exfoliation occurred versus chemical etching. Although the etching process increased both the micro- and meso-porosity (Figure 24), the results were not easily controllable, and the etching/exfoliation process led to a great deal of mesoporosity, that was not advantageous for $\mathrm{H}_{2}$ adsorption. Thus, the work shifted to other nanoporous carbons.

Figure 23: TEM of (a) chemically etched GNF of this work, and (b) EGNF of previous work. Latter is from ${ }^{1}$.
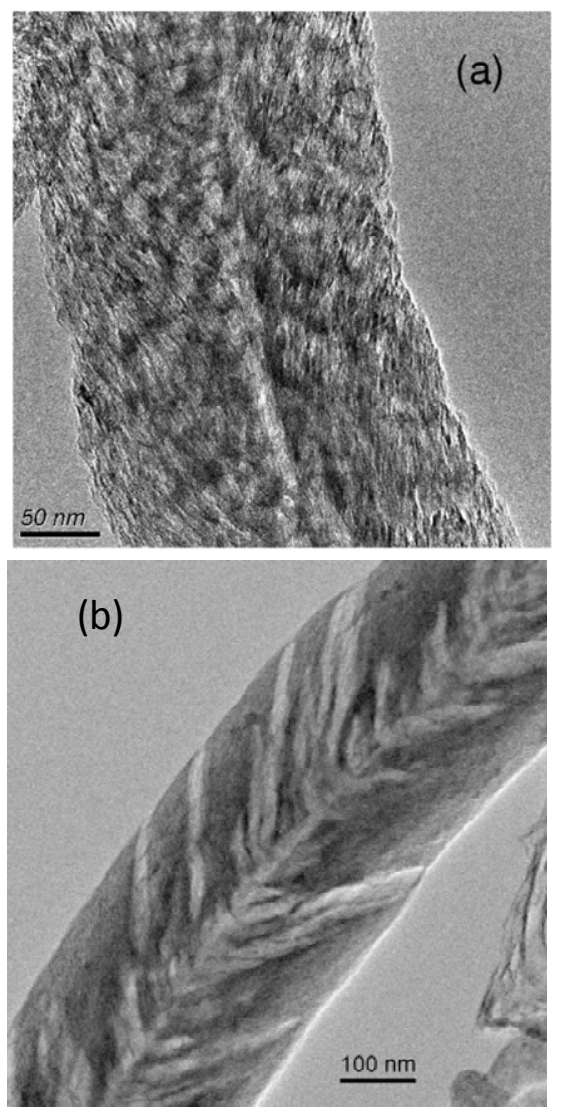

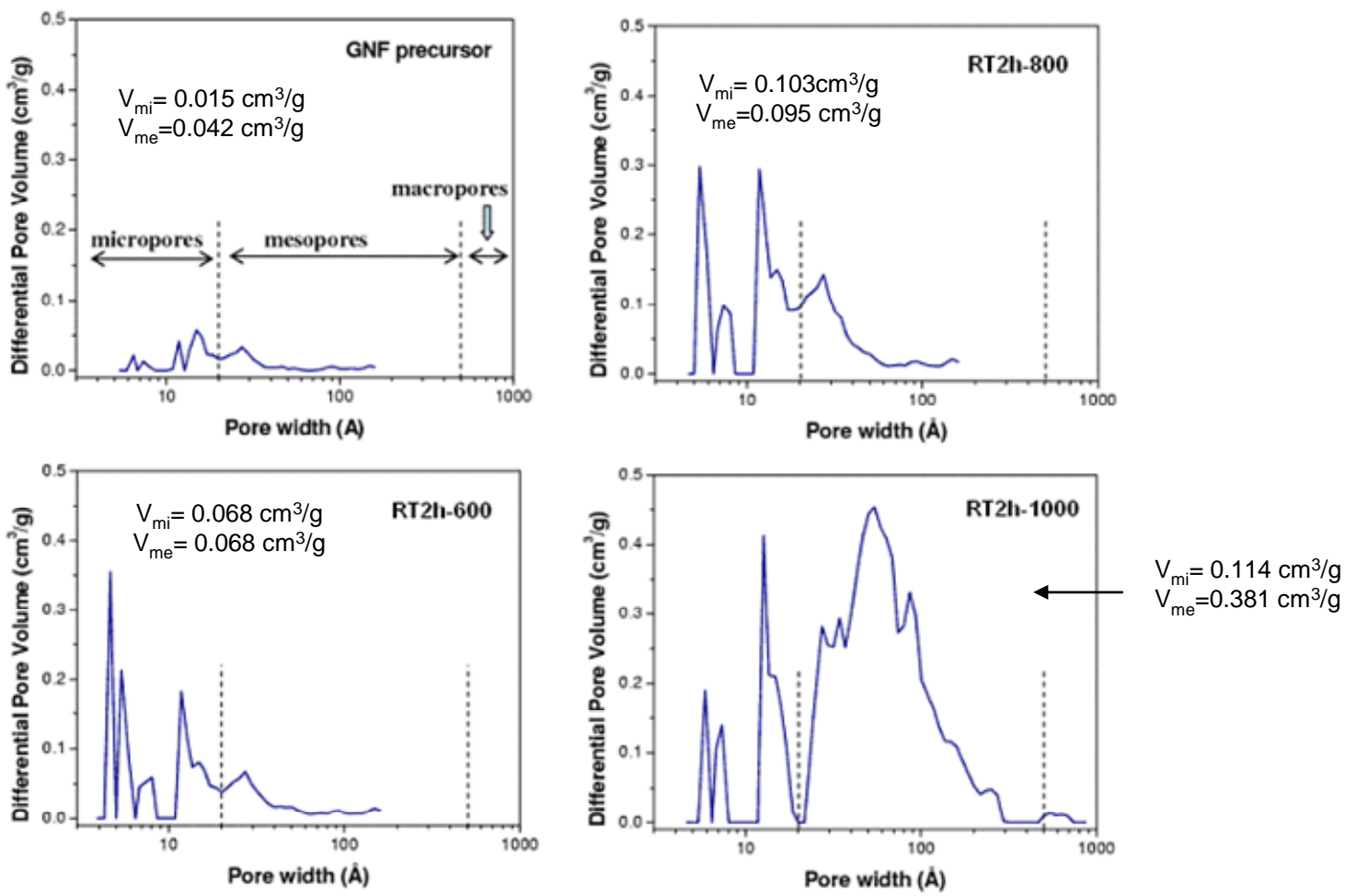

Figure 24: Variation of synthesis conditions of etched GNF led to differences in pore size distribution (as calculated by density functional theory). From ${ }^{1}$.
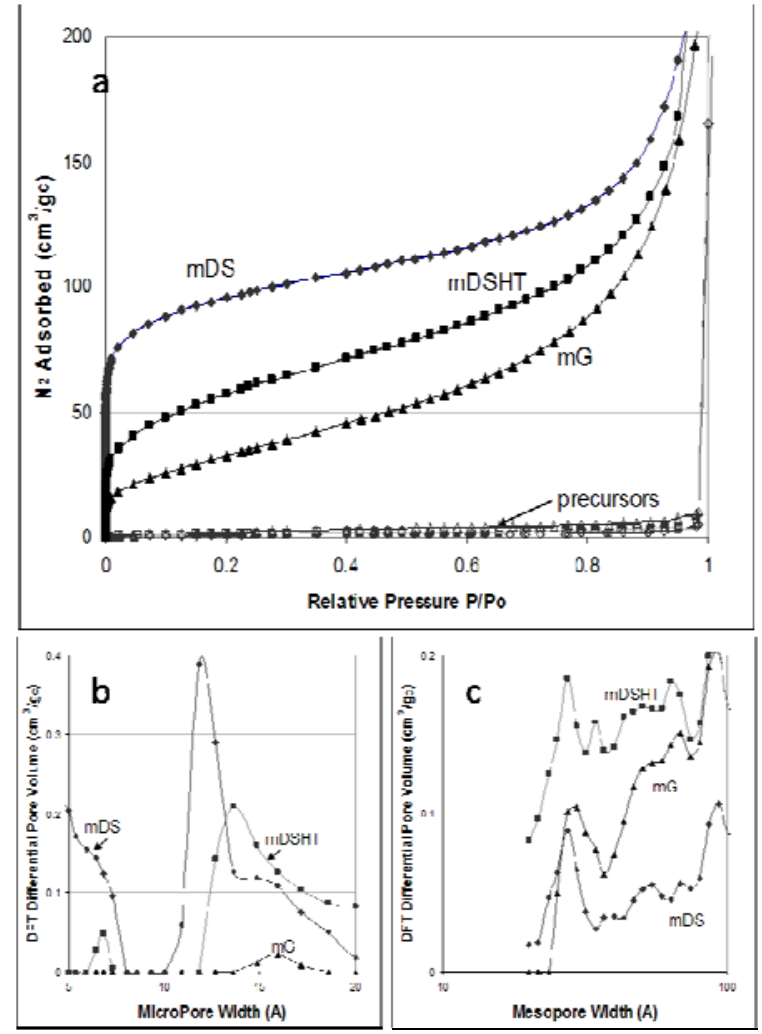

RBMA Characterization: As mentioned previously, RBMA was used to establish procedures towards the initial project objective of using high-pressure in situ characterization to understand, identify, and optimize specific adsorption sites. The work with RBMA was conducted in parallel to other (DOE-funded) projects working with this material. Other results related to synthesis and structure of RBMA were included in a peer-reviewed publication, ${ }^{44}$ with acknowledgement given to this funding. Information relevant to hydrogen storage is summarized briefly below.

Characterization of RBMA with gas adsorption indicates the synthesis process has a dramatic effect on porosity. Further, these materials may have a quite favorable pore size for adsorption (Figure 25): the ideal lattice spacing is estimated to be 6-7 $\AA$ based on theoretical predictions for exfoliated graphite $(\mathrm{EG})^{45,46}$ and a sizable distribution of pores formed from ball milling are in this range, or approximately double this range (see Figure 25). For comparison, the BET surface area of milled graphite increases $\sim 10$-fold with ball milling relative to graphite, and the increased surface area is primarily associated with mesopores, with only $\sim 0.7 \%$ of the

Figure 25: (a) Nitrogen adsorption at 77K, and corresponding (b) microporosity and (c) mesoporosity of the RBMA materials based on Density Functional Theory. Pore size distribution of precursors not shown, as the N2 uptake of these materials was minimal. From 44. 
total pore volume of milled graphite is attributable to micropores. In contrast the BET surface area of a RBMA increases a remarkable 80 -fold with ball milling. The microporosity makes up $23 \%$ of the pore volume of the RBMA (Figure 25), and a large fraction of the micro pore volume of the RBMA is ultra micorpores below $8 \AA$ (Figure 25). In this work, we also showed that the micropore volume (pore diameter $<20 \AA$, Figure 25b) follows decreasing carbon order of the precursor: The differential pore size distribution (Figure 25b) indicates the pores of the as-received anthracite were in the ultra-micropore range, whereas the pores of a thermally annealed anthracite were primarily $>10 \AA$; pores of milled graphite were primarily above $20 \AA$. Disorder in the carbon precursor appears to lead to a more 'tightly knit' structure upon reactive ball milling with pores in the molecular scale.

\section{Additional Unpublished Data}

CDC Work. CDCs were selected as an alternative to EGNFs in later work, as published data on CDCs indicated better ability to tune the porosity and surface

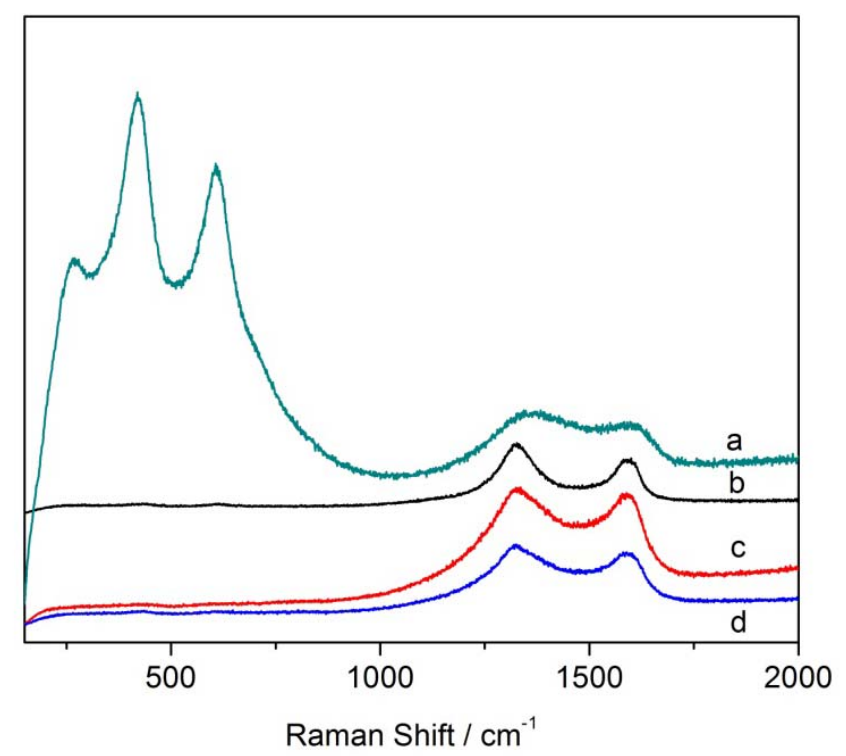

Figure 26: TiC-CDC synthesized at $600{ }^{\circ} \mathrm{C}$ at different time, a) original TiC; b) $1 \mathrm{hr}$; c) $2 \mathrm{hrs}$; d) $3 \mathrm{hrs}$. area. ${ }^{8}$ Our intent was to use CDCs as a nanoporous carbon support for hydrogen spillover and explore incomplete removal of the metal of the metal carbide precursor so that this metal may serve as the dissociation catalyst in the hydrogen spillover process. Towards the latter goal, synthesis time was varied to alter the Ti

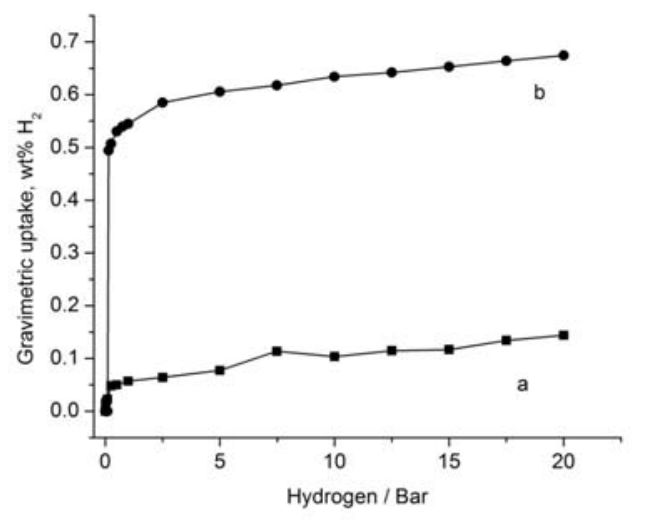

Figure 27: Hydrogen adsorption isotherms at $300 \mathrm{~K}$ of (a) TiC-CDC-600, and (b) mixed 9:1 with $5 \%$ Pd-C

$\mathrm{m}^{2} / \mathrm{g}$ (published), and $0.5 \mathrm{~cm}^{3} / \mathrm{g}$ (ours, Figure 6 of ${ }^{47}$ ) and $0.99 \mathrm{~cm}^{3} / \mathrm{g}$ (published), respectively. Hydrogen uptake of TiC-CDC (synthesized at $600{ }^{\circ} \mathrm{C}$ ) was measured at both 77 and $300 \mathrm{~K}$ (Fig. 7 of ${ }^{47}$ ), and was also lower than published data. Doping of TiC-CDC with Pd led to a $\sim 6$-fold enhancement of hydrogen uptake at $300 \mathrm{~K}$, and is attributed to the hydrogen spillover mechanism (Figure 27). However, the low surface area, pore volume, and hydrogen physisorption relative to published values, led (in part) to our use of commercial AC and $\mathrm{AC}-\mathrm{o}$ in subsequent studies. content of a TiC-derived CDC. Raman spectra collected at $633 \mathrm{~nm}$ indicates the complete conversion of titanium carbide to carbon takes place after 1 hour at $600{ }^{\circ} \mathrm{C}$ (Figure 26). As synthesis time increases, $\mathrm{D} / \mathrm{G}$ ratio decreases which means more ordered carbon is formed. However, XRD characterization (data now shown, see Quarterly Report 10) indicated that the TiC-CDC synthesized at $600{ }^{\circ} \mathrm{C}$ still had residual TiC. The pore size distribution of TiC-CDC synthesized at $600{ }^{\circ} \mathrm{C}$ and $3 \mathrm{hrs}$ (Fig. 5 of ${ }^{47}$ ) was qualitatively similar to published data, ${ }^{48}$ but the surface area was $\sim 80 \%$ lower than published, likely due to the lack of complete removal of the $\mathrm{TiC}$ precursor. The synthesis temperature was then elevated to $800{ }^{\circ} \mathrm{C}$ and $1000{ }^{\circ} \mathrm{C}$, but XRD indicated the TiC precursor was still present (data shown in Fig. 3 of ${ }^{47}$ ). When a $\mathrm{B}_{4} \mathrm{C}$ was used as the $\mathrm{CDC}$ precursor, no evidence of $\mathrm{B}_{4} \mathrm{C}$ precursor was found after 3 hours of reaction at $800{ }^{\circ} \mathrm{C}$ (data shown in Fig. 4 of ${ }^{47}$ ). Despite complete removal of $\mathrm{B}_{4} \mathrm{C}$, the measured BET surface area and pore volume were still lower than published values: $1353 \mathrm{~m}^{2} / \mathrm{g}$ (ours) vs. 2012 
Spillover to Carbon Nanotubes II (MWNT). Raman data were collected for MWNT (a) as-synthesized, and (b) after treatment in $\mathrm{H}_{2}$ on the IGA at $480{ }^{\circ} \mathrm{C}$ for $7 \mathrm{hrs}$ at ambient hydrogen atmosphere and following a 20 bar isotherm There is some indication that the hydrogen exposure changed the intensity of peaks that are attributable to $\mathrm{C}-\mathrm{H}$ interaction (i.e. Raman peaks at $2900 \mathrm{~cm}^{-1}$ ). These results are in agreement with the work of Zhang et al., ${ }^{49}$ which showed a similar increase in the $\mathrm{C}-\mathrm{H}$ interactions after $\mathrm{H}_{2}$ exposure. Comparing our Raman results to the results taken during hydrogen exposure in a high-pressure TGA suggests that the hydrogen uptake for these materials occurs as the sample is cooled from pretreatment temperatures to the adsorption temperature (Figure 28, similar to that discussed in the previous low-pressure spillover section), and is not a strong function of pressure (data not shown). In Raman, the signal-to-noise ratio for the MWNT sample after $\mathrm{H}_{2}$ exposure was high, and any changes after $\mathrm{H}_{2}$ exposure were extremely subtle (see Fig. 3 of ${ }^{50}$ ). We also note that the pretreatment of Zhang et al. included a higher pretreatment temperature $(873 \mathrm{~K}$ in vaccuo for 2 hours), a temperature which is beyond the capability of in situ monitoring in our high-pressure TGA. At the temperature of our pretreatment $\left(480{ }^{\circ} \mathrm{C}\right)$, we observed a $2.5 \%$ mass loss over the course of the pretreatment. The Zhang et al. pretreatment at $873 \mathrm{~K}$ may have led to partial catalytic gasification of the sample.

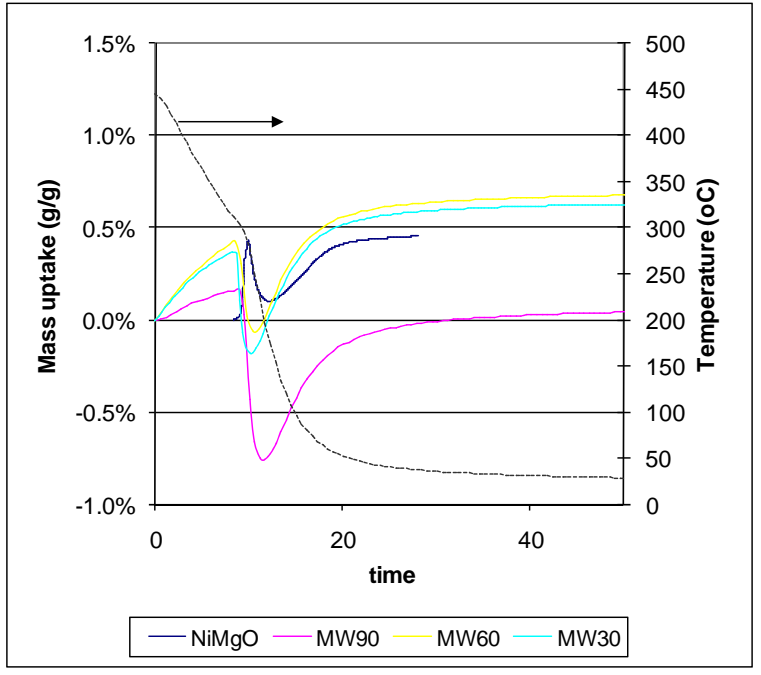

Figure 28: Hydrogen uptake for the MWNT samples synthesized with 30, 60, 90 minutes show that all hydrogen uptake occurs as the sample is cooled from the pretreatment temperature $\left(480{ }^{\circ} \mathrm{C}\right)$ to room temperature for the adsorption measurements. Less than $0.05 \%$ (by weight) uptake was observed in the high-pressure TGA with increasing pressure up to 20 bar. Gasification of the sample is anticipated to 'activate' the sample and create microposority that may facilitate hydrogen uptake. This work could potentially be revisited with Raman spectroscopy when/if a clear C-H dependence on hydrogen exposure was established. At that point, the effect of partial gasification could be studied in future work.

The uptake of different nanoporous carbons is compared in Figure 29. We note the uptake behavior of $1 \%$ $\mathrm{Pt} / \mathrm{SWNT}$ (from Figure 18) is qualitatively different than other metal-doped carbon samples. At 20 bar, 1\%

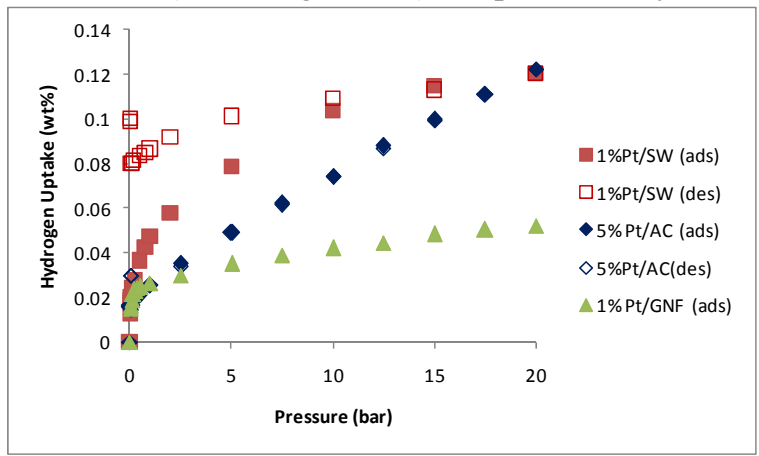

Figure 29: Hydrogen uptake for three metal-doped carbons. $1 \% \mathrm{Pt} / \mathrm{SWNT}$ has an uptake that is greater at low pressures and a greater amount of adsorptiondesorption hysteresis compared to a commercial $5 \%$ Pt/AC. Only adsorption data is shown for $1 \% \mathrm{Pt} / \mathrm{GNF}$.

incorporation into the synthesis of RBMA. Boron is an active area of research in doping of nanoporous carbons, in order to add an electron deficiency to the adsorbate to increase the interaction
$\mathrm{Pt} / \mathrm{SWNT}$ and $5 \% \mathrm{Pt} / \mathrm{AC}$ have the same amount of overall uptake, but the shape of the isotherm in the mid-pressure regime differs. A good deal of hysteresis is observed for $1 \%$ Pt/SWNT, while little to no hysteresis observed for $5 \%$ $\mathrm{Pt} / \mathrm{AC}$. The uptake of $1 \% \mathrm{Pt} / \mathrm{SWNT}$ is greater than $1 \%$ $\mathrm{Pt} / \mathrm{GNF}$, due either to difference in microporosity or metaldispersion. The intent here was to explore the differences between these samples with in situ characterization, however as discussed above, extreme subtleties in the Raman spectra led to redirection of these efforts.

Doping of GNF with MgB2. Methods to intercalate GNF with magnesium and boron were explored. Magnesium is a light weight metal, abundant, low cost, and the magnesium hydride (i.e. $\mathrm{MgH}_{2}$ ) contains as much as $7.6 \%$ hydrogen by weight which make it a promising material for hydrogen storage. In previous work, ${ }^{51}$ we have explored $\mathrm{Mg}$ the adsorbate to increase the interaction with $\mathrm{H}_{2}$. Co-doping 
of GNF with $\mathrm{MgB}_{2}$ led to insertion of boron and magnesium into the GNF matrix, based on evidence from XRD, TPO (Shown in ${ }^{52}$ ), HRTEM, EELS, and EDX (Figure 30). TPO measurements showed a considerable improvement on the nanofiber stability against oxidation for doped and HTT samples. The amount incorporated was low, and dependent upon crystalline structure and quality of the nanofiber (Figure 31). High-temperature treatment was used to improve the graphitic order in the nanofibers. These preliminary $\mathrm{GNF} / \mathrm{MgB}_{2}$ results were exploratory, and did not lead to appreciable hydrogen uptake. The synthesis results were relevant to the exfoliation process, but when the direction of the project shifted to other carbon materials due to issues with porosity for GNF and EGNF, these GNF-doping experiments were given low priority.
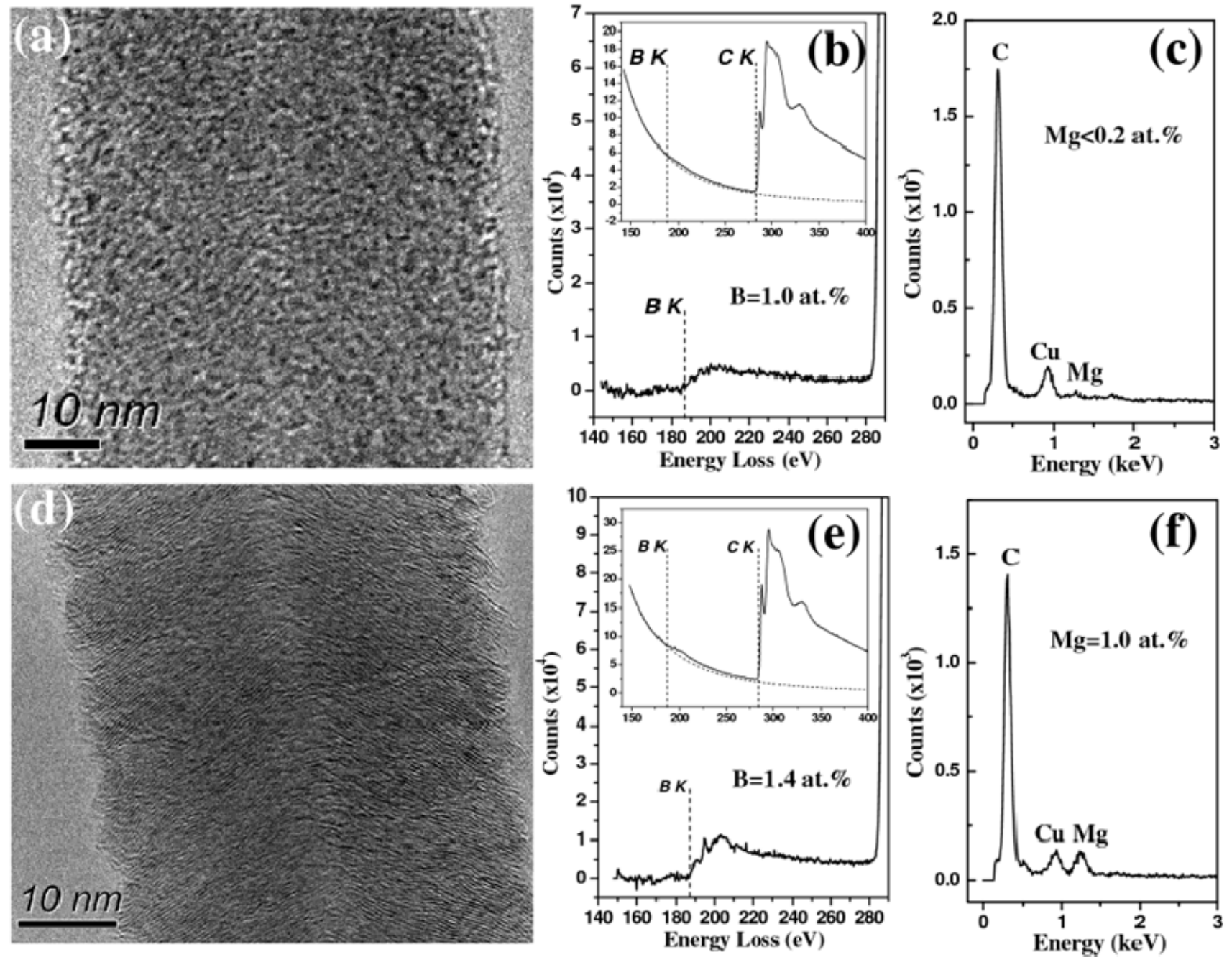

Figure 30: HRTEM (a, d), EELS (b, e) and EDS (c, f) spectra of two fibers with different crystalline quality. The EELS (b) and EDS (c) of nanofiber in (a) show a slightly lower concentrations of B and Mg in this nanofiber with little crystalline order. The crystalline planes in nanofiber (d) can be easily observed, in this case, the B (e) and Mg (f) concentrations are higher. 

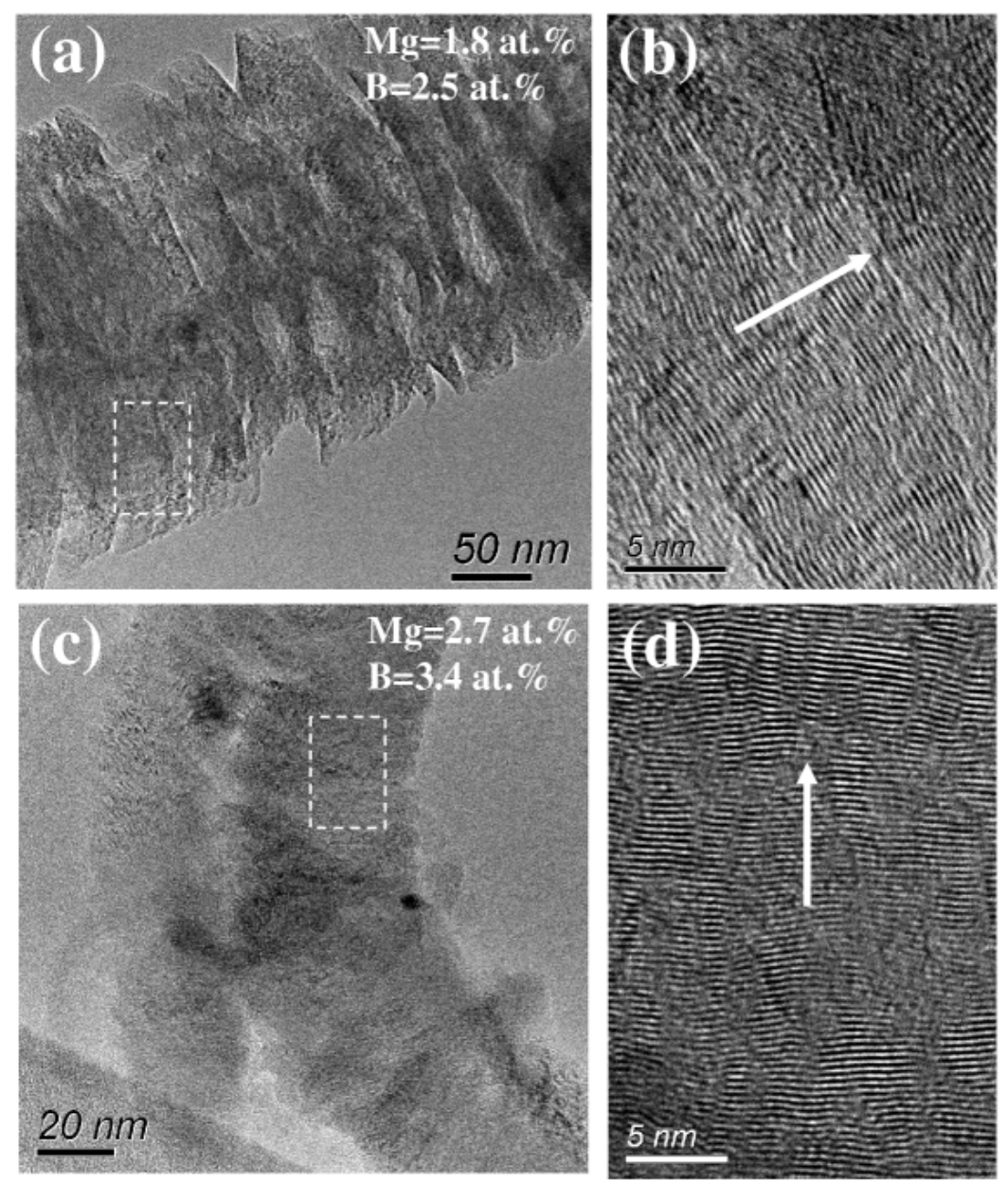

Figure 31: TEM (a, c) of two platelet-type nanofibers with different diameters: (a) $\mathrm{d} \sim 265 \mathrm{~nm}$ and (c) $\mathrm{d} \sim 58 \mathrm{~nm}$ and the corresponding atomic percentage of Mg and B measured by EDS and EELS. HRTEM (b,d) at the position indicated by the dashed rectangle in (a, c), respectively. The white arrows indicate the nanofiber axis, in both images the fringes corresponding to the graphene planes are perpendicular to the fiber axis. 

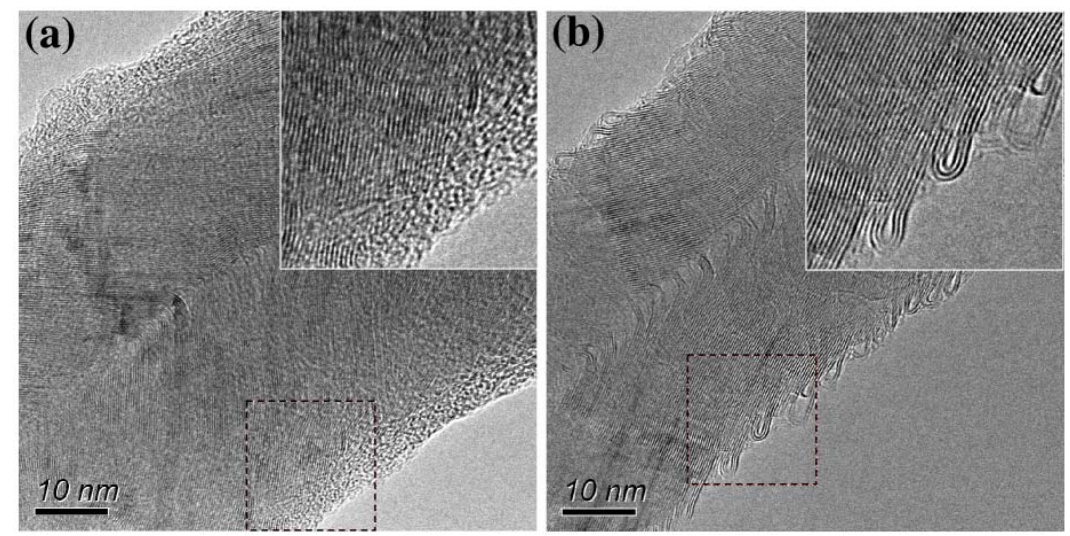

Figure 32: HRTEM images of: (a) HTT sample and (b) HTT sample with an additional treatment at 590 ${ }^{\circ} \mathrm{C}$ in dry air to remove amorphous carbons. The inset in the figures show how the thin outer amorphous layer formed during the HTT at $2000{ }^{\circ} \mathrm{C}$ was completely removed after the oxidation step. The inset in (b) also show the closed end (loops) of the graphitic layers.

\section{Conclusions}

The objective of the project was to understand the active adsorption sites in carbon materials that have been activated with nanocatalysts, and use this knowledge to enhance synergistic effects that create new adsorption sites and activate the carbon nanomaterials for adsorption in the DOE target temperature and pressure range. Activating the carbon materials with nanocatalysts includes optimizing the metal dispersion and the carbon acceptor sites. The present work focuses on the latter, which is optimizing the carbon acceptor site. The introduction of oxygen groups onto the surface of activated carbon, has been experimentally shown to lead to an enhancement of low-pressure hydrogen adsorption via the spillover process. However, trace water present during pretreatment plays an important role in the development of surface sites responsible for this lowpressure uptake. At $300 \mathrm{~K}$, the hydrogen uptake was up to $1.1 \mathrm{wt} \%$ at $100 \mathrm{mbar}$ and increased to $1.4 \mathrm{wt}$ \% at 20 bar. However, only $0.4 \mathrm{wt} \%$ of this was desorbable via a pressure reduction at room temperature, and the high low-pressure hydrogen uptake was found only when trace water was present during pretreatment. The uptake does not meet DOE targets for mobile applications (i.e. $5.5 \mathrm{wt} \%$ ), but is reported at 1000-fold reduction compared to the DOE pressure goal of 100 bar. Thus the isotherm shape of these hydrogen spillover materials is similar to that of metal hydrides rather than physical adsorption, and the operating conditions would require significantly less robust containers. Temperature-programmed desorption suggests desorption of hydrogen adsorbed to an oxidized carbon surface is highly dependent upon the nature of the surface sites.

High-pressure in situ characterization shows no evidence for rehybridization of idealized $\mathrm{sp}^{2}$ surfaces; evidence for carbon-hydrogen bond formation is found for amorphous carbon materials. High-pressure in situ methods did not provide conclusive data for a priori use in material design.

Various other nanoporous carbon materials were explored and developed. Few of these 'novel' nanoporous carbons showed properties advantageous when compared to standard, commerciallyavailable activated carbon, and thus efforts were redirected to explore the effect of changing surface chemistry on activated carbon. 


\section{GRAPHICAL MATERIALS LIST}

\section{Tables}

Table 1: Summary of textural properties of as-received and surface modified samples

Table 2: Surface composition of as-received AC, KOH-modified AC (AC-o) and Pt-C/AC-o at different experiment stages.

Table 3: Summary of Low-Pressure (Vacuum) Hydrogen Uptake Attributed to Hydrogen Spillover

\section{Figures}

Figure 1: Adsorption isotherms for LaNi5, (a) measured on the IGA, (b) from published data, and (c) measured at $20{ }^{\circ} \mathrm{C}$ on the volumetric equipment.

Figure 2: Volumetric adsorption data for GX-31 Amoco activated carbon matches published literature reports, thus verifying the measurement and the newly developed equipment. (a) ambient temperature of $25{ }^{\circ} \mathrm{C}$; (b) $0{ }^{\circ} \mathrm{C}$, and (c) $50{ }^{\circ} \mathrm{C}$.

Figure 3: Calibration of the TG-MS with calcium oxalate hydrate: (a) our equipment vs. (b) manufacturer data.

Figure 4: TPD spectra of Pd and Pd-C used to validate TPD Method-2. (A) $\mathrm{H}_{2}$ signal; (B) $\mathrm{H}_{2} \mathrm{O}$ signal. All signals were normalized on per gram basis.

Figure 5: TPD spectra of quartz after $\mathrm{H}_{2}$ adsorption at $250{ }^{\circ} \mathrm{C}$ suggests desorption from the internals of the stainless steel reactor is possible and must be considered in analysis of the TPD spectra. Here, sample was not degassed after adsorption prior to cooling to room temperature to take the TPD measurement.....

Figure 6: High resolution O 1s XPS spectra (dotted line) and curve fitting (solid line) of (A) AC and (B) AC-o. Peak I (531.1-531.6 eV) is assigned to oxygen in carbonyl or quinone groups. ${ }^{18,19}$ Peak II $(\sim 533.1 \mathrm{eV})$ is assigned to oxygen atoms in esters, carboxylic anhydrides and oxygen atoms in hydroxyls or ethers. ${ }^{18,20}$ Peak III indicates adsorbed water or oxygen ${ }^{19}$....................... 16 Figure 7: Effect of carbon oxidation in Set-up 1: Hydrogen isotherms $\left(25{ }^{\circ} \mathrm{C}\right)$ of $\mathrm{AC}, \mathrm{AC}-\mathrm{o}, 5 \%$ $\mathrm{Pt}-\mathrm{C}$, and $\mathrm{Pt}-\mathrm{C} / \mathrm{AC}-\mathrm{o}$. The isotherm of Pt-C/AC-o is indicative of hydrogen spillover, in that the hydrogen uptake of the physical mixture of the Pt-C catalyst and the secondary AC-o support exceed that expected if their individual contributions were additive. Isotherm of $\mathrm{AC}$ and $\mathrm{AC}-\mathrm{O}$ are overlapping with each other. Solid signs are representing adsorption, hollow signs are for desorption. Lines are used to lead the eyes.

Figure 8: Isotherms of Pt-C/AC-o $(25 \mathrm{oC})$ obtained in Set-up 2. (a) H2 adsorption after dry pretreatment, dPt-C/AC-o; (b) $\mathrm{H} 2$ adsorption after wet pretreatment (see text), wPt-C/AC-o; (c) $\mathrm{H} 2 \mathrm{O}$ adsorption after wet pretreatment (x-axis shows the total pressure of $\mathrm{He} / \mathrm{H} 2 \mathrm{O}$ mixture); and (d) $\mathrm{H} 2$ adsorption following evacuation after $\mathrm{H} 2 \mathrm{O}$ adsorption for (c). Data is plotted as total pressure of the system.

Figure 9: High resolution O 1s XPS spectra (dotted line) and curve fitting (solid line) of (a) assynthesized $\mathrm{Pt}-\mathrm{C} / \mathrm{AC}-\mathrm{o}$, (b) after dry pretreatment and $\mathrm{H} 2$ adsorption, $\mathrm{dPt}-\mathrm{C} / \mathrm{AC}$; and (c) after wet pretreatment and $\mathrm{H} 2$ adsorption, wPt-C/AC. Peak II increases in two post-adsorption samples. The area ratio of peak II to peak I for the three samples is $0.82,1.07$ and 1.49 , respectively. ..... 18 Figure 10: FTIR spectra of (a) as-synthesized Pt-C/AC-o, (b) after dry pretreatment and H2 adsorption, dPt-C/AC; and (c) after wet pretreatment and $\mathrm{H} 2$ adsorption, wPt-C/AC. All spectra were collected at $50 \mathrm{oC}$. Inset is the spectra after subtracting of background. 19 
Figure 11: TPD spectra of quartz (used as background signal test), oxidized AC (AC-o) and Ptdoped AC-o (Pt-C/AC-o). (A) Normalized H2 signal; (B) Normalized H2O signal. Pt-C/AC-o_a and $\mathrm{Pt}-\mathrm{C} / \mathrm{AC}-\mathrm{o} b$ designate samples from different batches..................................................... 19 Figure 12: TPD spectra of Pt-C/AC-o_c using TPD-Method 2 (quenching to $77 \mathrm{~K}$ prior to heating). Green line represents $\mathrm{H}_{2}$ signal, red line represents $\mathrm{H}_{2} \mathrm{O}$ signal................................ 20 Figure 13: Visible Raman (633 $\mathrm{nm}$ and $514 \mathrm{~nm}$ ) of graphite ball milled in cyclohexene at 1 bar. The origin of the peak at $4250 \mathrm{~cm}-1(514 \mathrm{~nm}, *)$ is being further explored. Ball milled carbons (and RBMAs) were used to establish procedures for Multi-wavelength Raman methods........... 21 Figure 14: Raman spectra of (a) gaseous $\mathrm{H}_{2}$ at $\sim 130 \mathrm{~atm}$, (b) the anthracite coal precursor, and the ball milled sample (c) one year and (d) one week after preparation. The upper portion of the graph presents the region of interest to $\mathrm{H}_{2}$, while the lower portion of the graph presents the usual carbon vibrations (D at $1310, \mathrm{G}$ at $1600 \mathrm{~cm}^{-1}$ ). 21

Figure 15: Variation of the RBMA carbon features in UV Raman shows unusual G-peak splitting and a suspected diamond peak at $1331 \mathrm{~cm}^{-1}$.... 22

Figure 16: MWR of RBMA at various stages of preparation (a-c are sequential stages) was used to 'validate' carbon-hydrogen interactions. Numbers shown indicate the Raman excitation frequency. .. 22 Figure 17: High pressure in situ Raman characterization of RBMA: (a) in $2000 \mathrm{psi}_{2}$, (b) in air. Referenced in the text are the D peak at $1351 \mathrm{~cm}^{-1}$; G peak at $1625 \mathrm{~cm}^{-1}$, both are characteristic for carbon materials. A peak at $3080 \mathrm{~cm}^{-1}$ is suggestive of a carbon-hydrogen bond................. 23 Figure 18: Gravimetric adsorption on $1 \% \mathrm{Pt} / \mathrm{SWNT}$ at $300 \mathrm{~K}$ is typical of hydrogen spillover, and exhibits appreciable adsorption-desorption hysteresis. 24 Figure 19: Raman spectroscopy for a $1 \% \mathrm{Pt} / \mathrm{SWNT}$ series at various stages of synthesis and hydrogen exposure: (1) after 1\% platinum doping of SWNT; (2) following reduction at $200{ }^{\circ} \mathrm{C}$ and a 20 bar $\mathrm{H}_{2}$ isotherm; (c) following a second $200{ }^{\circ} \mathrm{C}$ reduction in $\mathrm{H}_{2}$ and transfer in an inert atmosphere, and (d) exposure of (c) to $100 \mathrm{bar}_{2}$ in situ in the capillary tube. All Raman data were collected in a capillary tube; (a-b) were collected in air; (c) in Argon; and (d) in highpressure $\mathrm{H}_{2}$. 24

Figure 20: Raman Spectroscopy of 1\% Pt/SWNT: (a) as-synthesized; (b) following exposure to $\mathrm{H}_{2}$ at $200{ }^{\circ} \mathrm{C}$ and $1 \mathrm{bar}$, then $25{ }^{\circ} \mathrm{C}$ and 20 bar; (c) replacing $\mathrm{H}_{2}$ with $\mathrm{He}$ during the $200{ }^{\circ} \mathrm{C}$ exposure, and (d) exposure of (b) to $100 \mathrm{bar}_{2}$ in situ on the Raman spectrometer.................... 25 Figure 21: Radial breathing mode (RBM) of SWCNTs heated at different temperatures in high pressure $\mathrm{H}_{2}$ atmosphere $\left(\mathrm{E}_{\text {laser }}=2.41 \mathrm{eV}\right)$. 25 Figure 22: Transverse modes of SWCNTs showed temperature dependence with a Raman excitation of $514 \mathrm{~nm}$ (left), but not at $633 \mathrm{~nm}$ (right). SWNT is heated in $100 \mathrm{bar} \mathrm{H}_{2}$ at the indicated temperatures. All data is collected after cooling back to room temperature................. 26 Figure 23: TEM of (a) chemically etched GNF of this work, and (b) EGNF of previous work. Latter is from ${ }^{1}$...... 27 Figure 24: Variation of synthesis conditions of etched GNF led to differences in pore size

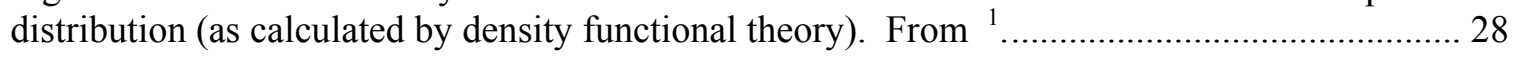
Figure 25: (a) Nitrogen adsorption at $77 \mathrm{~K}$, and corresponding (b) microporosity and (c) mesoporosity of the RBMA materials based on Density Functional Theory. Pore size distribution of precursors not shown, as the N2 uptake of these materials was minimal. From 44.............. 28 Figure 26: TiC-CDC synthesized at $600{ }^{\circ} \mathrm{C}$ at different time, a) original TiC; b) $1 \mathrm{hr}$; c) $2 \mathrm{hrs}$; d)

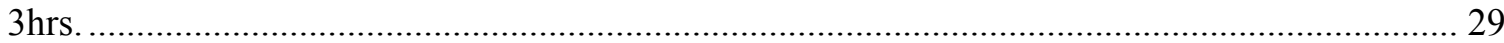
Figure 27: Hydrogen adsorption isotherms at 300K of (a) TiC-CDC-600, and (b) mixed 9:1 with $5 \% \mathrm{Pd}-\mathrm{C}$

Figure 28: Hydrogen uptake for the MWNT samples synthesized with 30, 60, 90 minutes show that all hydrogen uptake occurs as the sample is cooled from the pretreatment temperature (480 ${ }^{\circ} \mathrm{C}$ ) to room temperature for the adsorption measurements. Less than $0.05 \%$ (by weight) uptake was observed in the high-pressure TGA with increasing pressure up to $20 \mathrm{bar}$. 30 
Figure 29: Hydrogen uptake for three metal-doped carbons. 1\% Pt/SWNT has an uptake that is greater at low pressures and a greater amount of adsorption-desorption hysteresis compared to a commercial 5\% Pt/AC. Only adsorption data is shown for $1 \% \mathrm{Pt} / \mathrm{GNF}$.

Figure 30: HRTEM (a, d), EELS (b, e) and EDS (c, f) spectra of two fibers with different crystalline quality. The EELS (b) and EDS (c) of nanofiber in (a) show a slightly lower concentrations of $\mathrm{B}$ and $\mathrm{Mg}$ in this nanofiber with little crystalline order. The crystalline planes in nanofiber (d) can be easily observed, in this case, the B (e) and $\mathrm{Mg}$ (f) concentrations are higher.

Figure 31: TEM (a, c) of two platelet-type nanofibers with different diameters: (a) d 265nm and (c) $\mathrm{d} \sim 58 \mathrm{~nm}$ and the corresponding atomic percentage of $\mathrm{Mg}$ and $\mathrm{B}$ measured by EDS and EELS. HRTEM $(b, d)$ at the position indicated by the dashed rectangle in $(a, c)$, respectively. The white arrows indicate the nanofiber axis, in both images the fringes corresponding to the graphene planes are perpendicular to the fiber axis. 32 Figure 32: HRTEM images of: (a) HTT sample and (b) HTT sample with an additional treatment at $590{ }^{\circ} \mathrm{C}$ in dry air to remove amorphous carbons. The inset in the figures show how the thin outer amorphous layer formed during the HTT at $2000{ }^{\circ} \mathrm{C}$ was completely removed after the oxidation step. The inset in (b) also show the closed end (loops) of the graphitic layers. 33

\section{REFERENCES}

1. Fonseca, D. A.; Gutierrez, H. R.; Lueking, A. D., Morphology and porosity enhancement on graphite nanofibers through chemical etching. Micropor Mesopor Mat 2008, 113 (1-3), 178186.

2. Lueking, A. D.; Pan, L.; Narayanan, D.; Burgess-Clifford, C. E., Effect of Expanded Graphite Lattice in Exfoliated Graphite Nanofibers on Hydrogen Storage. J. Phys. Chem. B. 2005, 109 (26), 12710-12717.

3. Fonseca, D. A.; Gutierrez, H. R.; Lueking, A. D., Influence of Thermal Treatment on the Structure of Exfoliated Graphite Nanofibers. Prepr. Pap.-Am. Chem. Soc., Div. Fuel Chem. 2006, $51(2)$.

4. Lueking, A. D.; Gutierrez, H. R.; Fonseca, D. A.; Dickey, E., Characterization of Exfoliated Graphite Nanofibers. Carbon 2007, 45, 751-759.

5. Jain, P. Catalyzed Nanocarbons for Hydrogen Storage: Experimental and Theoretical Study of the Spillover Phenomenon. Masters Thesis, Pennsylvania State University, University Park, 2006.

6. $\quad$ Chen, W. X.; De Xu, Z.; Tu, J. P.; Liu, Z. J.; Jin, Y. X.; Lv, D. Y.; Lu, X. N., Synthesis of carbon nanotubes by catalytic chemical vapor deposition using hydrogen storage alloy as a catalyst. Chinese Chem Lett 2001, 12 (6), 545-548.

7. Lueking, A. D.; Gutierrez, H. R.; Fonseca, D. A.; Narayanan, D. L.; VanEssendelft, D.; Jain, P.; Clifford, C. E. B., Combined Hydrogen Production and Storage with Subsequent Carbon Crystallization. J. Am. Chem. Soc. 2006, 128 (24), 7758-7760.

8. Gogotsi, Y.; Nikitin, A.; Ye, H. H.; Zhou, W.; Fischer, J. E.; Bo, Y.; Foley, H. C.; Barsoum, M. W., Nanoporous carbide-derived carbon with tunable pore size. Nat. Mater. 2003, 2 (9), 591-594.

9. Gogotsi, Y.; Dash, R. K.; Yushin, G.; Yildirim, T.; Laudisio, G.; Fischer, J. E., Tailoring of nanoscale porosity in carbide-derived carbons for hydrogen storage. Journal of the American Chemical Society 2005, 127 (46), 16006-16007. 
10. Chiang, H. L.; Huang, C. P.; Chiang, P. C., The surface characteristics of activated carbon as affected by ozone and alkaline treatment. Chemosphere 2002, 47 (3), 257-265.

11. Lueking, A. D.; Liu, X.; Li, Q.; Sakti, A.; Wonderling, N. W., Multi-wavelength Raman Spectroscopy of Reactively Ball Milled Anthracite as a Probe of Carbon Structural Transformations. In Progress. Expected Submission 2010.

12. Takahagi, T.; Ishitani, A., XPS studies by use of the digital difference spectrum technique of functional-groups on the surface of carbon-fiber. Carbon 1984, 22 (1), 43-46.

13. Jain, P.; Fonseca, D. A.; Schaible, E.; Lueking, A. D., Hydrogen uptake of platinumdoped graphite nanoribers and stochastic analysis of hydrogen spillover. J. Phys. Chem. C 2007, 111 (4), 1788-1800.

14. Srinivas, S. T.; Rao, P. K., Direct Observation of Hydrogen Spillover on CarbonSupported Platinum and Its Influence on the Hydrogenation of Benzene. J. Catal. 1994, 148 (2), 470-477.

15. Browning, D. J.; Gerrard, M. L.; Lakeman, J. B.; Mellor, I. M.; Mortimer, R. J.; Turpin, M. C., Studies into the storage of hydrogen in carbon nanofibers: Proposal of a possible reaction mechanism. Nano Lett 2002, 2 (3), 201-205.

16. Zielinski, J. M.; Coe, C. G.; Nickel, R. J.; Romeo, A. M.; Cooper, A. C.; Pez, G. P., High Pressure Sorption Isotherms via Differential Pressure Measurements. Adsorption 2006, In Press.

17. Li, Q.; Lueking, A. D., The Effect of Surface Oxygen Groups and Water on Hydrogen Spillover in Pt-doped Activated Carbon. Journal of Physical Chemistry C 2010, Submitted.

18. Laszlo, K.; Tombacz, E.; Josepovits, K., Effect of activation on the surface chemistry of carbons from polymer precursors. Carbon 2001, 39 (8), 1217-1228.

19. Zhou, J. H.; Sui, Z. J.; Zhu, J.; Li, P.; De, C.; Dai, Y. C.; Yuan, W. K., Characterization of surface oxygen complexes on carbon nanofibers by TPD, XPS and FT-IR. Carbon 2007, 45 (4), 785-796.

20. Desimoni, E.; Casella, G. I.; Salvi, A. M.; Cataldi, T. R. I.; Morone, A., XPS Investigation of Ultra-High-Vacuum Storage Effects on Carbon-Fiber Surfaces. Carbon 1992, 30 (4), 527-531.

21. Wang, Z.; Yang, F. H.; Yang, R. T., Enhanced Hydrogen Spillover on Carbon Surfaces Modified by Oxygen Plasma. J. Phys. Chem. C 2010, 114 (3), 1601-1609.

22. Psofogiannakis, G. M.; Froudakis, G. E., DFT Study of Hydrogen Storage by Spillover on Graphite with Oxygen Surface Groups. J. Am. Chem. Soc. 2009, 131 (42), 15133.

23. Salame, II; Bandosz, T. J., Surface chemistry of activated carbons: Combining the results of temperature-programmed desorption, boehm, and potentiometric titrations. J. Colloid Interface Sci. 2001, 240 (1), 252-258.

24. Miller, J. T.; Meyers, B. L.; Modica, F. S.; Lane, G. S.; Vaarkamp, M.; Koningsberger, D. C., Hydrogen Temperature-Programmed Desorption ( $\mathrm{H}_{2}$ TPD) of Supported Platinum Catalysts. J. Catal. 1993, 143 (2), 395-408.

25. Amorim, C.; Keane, M. A., Palladium supported on structured and nonstructured carbon: A consideration of Pd particle size and the nature of reactive hydrogen. J. Colloid Interface Sci. 2008, 322 (1), 196-208.

26. Ros, T. G.; van Dillen, A. J.; Geus, J. W.; Koningsberger, D. C., Surface oxidation of carbon nanofibres. Chem.-Eur. J. 2002, 8 (5), 1151-1162.

27. Kundu, S.; Wang, Y. M.; Xia, W.; Muhler, M., Thermal Stability and Reducibility of Oxygen-Containing Functional Groups on Multiwalled Carbon Nanotube Surfaces: A Quantitative High-Resolution XPS and TPD/TPR Study. J. Phys. Chem. C 2008, 112 (43), 16869-16878.

28. Dresselhaus, M. S.; Dresselhaus, G.; Pimenta, M. A.; Eklund, P. C., Raman Scattering in Carbon Materials. In Analytical Applications of Raman Spectroscopy, Pelletier, M. J., Ed. Blackwell Science: Ann Arbor, 1999; pp 367-434. 
29. Orimo, S.; Matsushima, T.; Fujii, H.; Fukunaga, T.; Majer, G., Hydrogen desorption property of mechanically prepared nanostructured graphite. J Appl Phys 2001, 90 (3), 1545-1549.

30. Lueking, A. D.; Badding, J. V. Quarterly Report: Development of Doped Nanoporous Carbons for Hydrogen Storage; University Coal Research Program, National Energy Technology Laboratory: April 13, 2006.

31. Atkins, P. W.; De Paula, J., Physical chemistry. 8th ed.; W.H. Freeman: New York, 2006; p.1053

32. Sharma, S. K.; Mao, H. K.; Bell, P. M., Raman Measurements of Hydrogen in the Pressure Range 0.2-630 Kbar at Room-Temperature. Phys Rev Lett 1980, 44 (13), 886-888.

33. Pradhan, B. K.; Sumanasekera, G. U.; Adu, K. W.; Romero, H. E.; Williams, K. A.; Eklund, P. C., Experimental probes of the molecular hydrogen-carbon nanotube interaction. Physica B 2002, 323 (1-4), 115-121.

34. Centrone, A.; Brambilla, L.; Zerbi, G., Adsorption of H-2 on carbon-based materials: A Raman spectroscopy study. Phys Rev B 2005, 71 (24), 245406.

35. Leitch, A. W. R.; Weber, J.; Alex, V., Formation of hydrogen molecules in crystalline silicon. Mat Sci Eng B-Solid 1999, 58 (1-2), 6-12.

36. Casiraghi, C.; Ferrari, A. C.; Robertson, J., Raman spectroscopy of hydrogenated amorphous carbons. Phys Rev B 2005, 72 (8), 085401.

37. Piscanec, S.; Mauri, F.; Ferrari, A. C.; Lazzeri, M.; Robertson, J., Ab initio resonant Raman spectra of diamond-like carbons. Diam Relat Mater 2005, 14 (3-7), 1078-1083.

38. Zhang, Y. Y.; Xie, L. M.; Zhang, J.; Wu, Z. Y.; Liu, Z. F., Temperature coefficients of Raman frequency of individual single-walled carbon nanotubes. Journal of Physical Chemistry $C$ 2007, 111 (38), 14031-14034.

39. Alvarez, L.; Righi, A.; Rols, S.; Anglaret, E.; Sauvajol, J. L., Excitation energy dependence of the Raman spectrum of single-walled carbon nanotubes. Chemical Physics Letters 2000, 320 (5-6), 441-447.

40. Badding, J. V.; Lueking, A. D., Reversible high pressure sp2-sp3 transformations in carbon. Phase Transitions 2007, 80 (10-12), 1033-1038.

41. Li, Q.; Lueking, A. D.; Badding, J. V., High-Pressure In Situ Characterization of Hydrogen Spillover in Pt-doped Single-Walled Carbon Nanotubes. In Preparation 2010.

42. Lueking, A. D.; Li, Q. Quarterly Report: Development of Doped Nanoporous Carbons for Hydrogen Storage; University Coal Research Program, National Energy Technology Laboratory: January 30, 2008.

43. Li, Q.; Lueking, A. D., Evidence for Hydrogen Spillover at Extremely Low Pressure for Pt- and Pd- supported on Carbon Materials. In Preparation 2008.

44. Sakti, A.; Wonderling, N. W.; Clifford, C. E. B.; Badding, J. V.; Lueking, A. D., Role of Carbon Order on Structural Transformations and Hydrogen Evolution Induced by Reactive Ball Milling in Cyclohexene. J. Phys. Chem. C. 2008, 112 (44), 17427-17435.

45. Patchkovskii, S.; Tse, J. S.; Yurchenko, S. N.; Zhechkov, L.; Heine, T.; Seifert, G., Graphene nanostructures as tunable storage media for molecular hydrogen. Proceedings of the National Academy of Sciences 2005, 102 (30), 10439-10444.

46. Kowalczyk, P.; Tanaka, H.; Holyst, R.; Kaneko, K.; Ohmori, T.; Miyamoto, J., Storage of hydrogen at $303 \mathrm{~K}$ in graphite slitlike pores from grand canonical Monte Carlo simulation. $J$ Phys Chem B 2005, 109 (36), 17174-17183.

47. Li, Q.; Badding, J. V.; Lueking, A. D. Quarterly Report: Development of Doped Nanoporous Carbons for Hydrogen Storage; University Coal Research Program, National Energy Technology Laboratory: July 30, 2008.

48. Yushin, G.; Dash, R.; Jagiello, J.; Fischer, J. E.; Gogotsi, Y., Carbide-derived carbons: Effect of pore size on hydrogen uptake and heat of adsorption. Advanced Functional Materials 2006, 16 (17), 2288-2293. 
49. Zhang, H. B.; Lin, G. D.; Zhou, Z. H.; Dong, X.; Chen, T., Raman spectra of MWCNTs and MWCNT-based H-2-adsorbing system. Carbon 2002, 40 (13), 2429-2436.

50. Li, Q.; Badding, J. V.; Lueking, A. D. Quarterly Report: Development of Doped Nanoporous Carbons for Hydrogen Storage; University Coal Research Program, National Energy Technology Laboratory: July 11, 2007.

51. Narayanan, D. L.; Lueking, A. D., Mechanically milled coal and magnesium composites for hydrogen storage. Carbon 2007, 45 (4), 805-820.

52. Fonseca, D. A.; Badding, J. V.; Lueking, A. D. Quarterly Report: Development of Doped Nanoporous Carbons for Hydrogen Storage; University Coal Research Program, National Energy Technology Laboratory: July 28, 2006.

\section{BIBLIOGRAPHY}

\section{STUDENTS SUPPORTED UNDER THIS GRANT}

Qixiu Li, Ph.D. Student, Department of Energy \& Geo-Environmental Engineering (funded 1/1/2007-3/1/2010).

Michael Schimmel, Ph.D. Student, Department of Chemistry, (1/1/-2006-8/1/2006).

Apurba Sakti, M.S. Student, Department of Energy \& Geo-Environmental Engineering (temporary substitute, hired 25\%,8/1/2006-12/31/2006)

Dr. Dania A. Fonseca, Post-doctoral Research Assistant, Energy Institute, Pennsylvania State University $(100 \%$ time $1 / 1 / 2006-10 / 15-2006,50 \%$ time $10 / 15 / 2006-12 / 31 / 2006 ; \sim 10 \%$ time $1 / 1 / 2007-2 / 28 / 2007)$.

\section{PAPERS PUBLISHED UNDER THIS GRANT}

Badding, J. V.; Lueking, A. D., Reversible high pressure sp2-sp3 transformations in carbon. Phase Transitions 2007, 80 (10-12), 1033-1038.

Fonseca, D. A.; Gutierrez, H. R.; Lueking, A. D., Morphology and porosity enhancement on graphite nanofibers through chemical etching. Micropor Mesopor Mat 2008, 113 (1-3), 178-186.

Sakti, A.; Wonderling, N. W.; Clifford, C. E. B.; Badding, J. V.; Lueking, A. D., Role of Carbon Order on Structural Transformations and Hydrogen Evolution Induced by Reactive Ball Milling in Cyclohexene. J. Phys. Chem. C. 2008, 112 (44), 17427-17435.

Li, Q.; Lueking, A. D., The Effect of Surface Oxygen Groups and Water on Hydrogen Spillover in Pt-doped Activated Carbon. Journal of Physical Chemistry C 2010, Submitted. 
Lueking, A. D.; Liu, X.; Li, Q.; Sakti, A.; Wonderling, N. W., Multi-wavelength Raman Spectroscopy of Reactively Ball Milled Anthracite as a Probe of Carbon Structural Transformations. In Preparation 2010.

Li, Q.; Lueking, A. D., Evidence for Hydrogen Spillover at Extremely Low Pressure for Pt- and Pd- supported on Carbon Materials. In Preparation 2010.

Li, Q.; Lueking, A. D., Hydrogen/Water Desorption Temperatures from Oxygen-Modified Carbon-Based Spillover Materials. In Preparation 2010.

Li, Q.; Lueking, A. D.; Badding, J. V., High-Pressure In Situ Characterization of Hydrogen Spillover in Pt-doped Single-Walled Carbon Nanotubes. In Preparation 2010. 


\section{LIST OF ACRONYNMS AND ABBREVIATIONS}

AC - Activated Carbon

AC-o - Activated Carbon, subjected to $\mathrm{KOH}$ oxidation treatment

DRIFTS - Diffuse reflectance infrared spectra

EDS - Energy-Dispersive X-ray Spectroscopy

EELS - Electron Energy Loss Spectroscopy (EELS)

EGNF - Exfoliated Graphite Nanofibers

FTIR - Fourier Transform Infrared Spectroscopy

GNF - Graphite Nanofibers

GX-31 - Trade name for an activated carbon used for equipment validation

HRTEM - High-Resolution Transmission Electron Microscopy

MWNT - Multi-walled carbon nanotube

MWR - Multi-wavelength micro-Raman spectroscopy

MS - Mass spectrometer ; Mass spectroscopy

RBM - Radial Breathing Modes [of SWNT]

RBMA - reactively Ball-milled anthracites

RBMA - Reactively Ball-milled graphite

SWNT - Single-walled Carbon Nanotube

TPO - Temperature-Programmed Oxidation

TEM - Transmission Electron Microscopy

TPD -Temperature-Programmed Desorption

XPS -X-ray Photoelectron Spectroscopy

XRD -X-ray Diffraction 